\title{
Characterization of introgression from the teosinte Zea mays ssp. mexicana to Mexican highland maize
}

\author{
Eric Gonzalez-Segovia ${ }^{1}$, Sergio Pérez-Limon ${ }^{1}$, G. Carolina Cíntora-Martínez ${ }^{1}$, Alejandro Guerrero-Zavala ${ }^{1}$, Garrett \\ M Janzen ${ }^{2}$, Matthew B Hufford ${ }^{2}$, Jeffrey Ross-Ibarra ${ }^{3}$, Ruairidh J H Sawers ${ }^{\text {Corresp. } 1}$ \\ 1 Unidad de Genómica Avanzada (LANGEBIO), Centro de Investigación y de Estudios Avanzados del Instituto Politécnico Nacional, Irapuato, Guanajuato, \\ Mexico \\ 2 Department of Ecology, Evolution, and Organismal Biology, lowa State University, Ames, United States \\ 3 Department of Plant Sciences, Center for Population Biology, and Genome Center, University of California, Davis, Davis, United States \\ Corresponding Author: Ruairidh J H Sawers \\ Email address: rusawers@cinvestav.mx
}

Background. The spread of maize cultivation to the highlands of central Mexico was accompanied by substantial introgression from the endemic wild teosinte Zea mays ssp. mexicana, prompting the hypothesis that the transfer of beneficial variation facilitated local adaptation.

Methods. We used whole-genome sequence data to map regions of Zea mays ssp. mexicana introgression in three Mexican highland maize individuals. We generated a genetic linkage map and performed Quantitative Trait Locus mapping in an $\mathrm{F}_{2}$ population derived from a cross between lowland and highland maize individuals.

Results. Introgression regions ranged in size from several hundred base pairs to Megabase-scale events. Gene density within introgression regions was comparable to the genome as a whole, and over one thousand annotated genes were located within introgression events. Quantitative Trait Locus mapping identified a small number of loci linked to traits characteristic of Mexican highland maize.

Discussion. Although there was no strong evidence to associate quantitative trait loci with regions of introgression, we nonetheless identified many Mexican highland alleles of introgressed origin that carry potentially functional sequence variants. The impact of introgression on stress tolerance and yield in the highland environment remains to be fully characterized. 
1 Title: Characterization of introgression from the teosinte Zea mays ssp. mexicana to Mexican

2 highland maize

3 Running Title: Teosinte introgression to maize

4 Area 4: Molecular Ecology and Evolution

5 Eric Gonzalez-Segovia ${ }^{1 *}$, Sergio Pérez-Limon ${ }^{1}$, G. Carolina Cíntora-Martínez ${ }^{1 \dagger}$, Alejandro

6 Guerrero-Zavala ${ }^{1}$, Garrett M. Janzen², Matthew B. Hufford ${ }^{2}$, Jeffrey Ross-Ibarra ${ }^{3}$, Ruairidh J. H.

7 Sawers $1+$

$8{ }^{1}$ Unidad de Genómica Avanzada (LANGEBIO), Centro de Investigación y de Estudios

9 Avanzados del Instituto Politécnico Nacional, Irapuato, Guanajuato, Mexico

$10{ }^{2}$ Department of Ecology, Evolution, and Organismal Biology, Iowa State University, Ames,

11 United States

$12{ }^{3}$ Department of Plant Sciences, Center for Population Biology, and Genome Center, University

13 of California, Davis, Davis, United States

14 *present address: School of Life Sciences, Technical University of Munich, Freising, Germany.

15 tpresent address: Max Planck Institute for Plant Breeding Research, Cologne, Germany.

16 †present address: Department of Plant Science, Pennsylvania State University, State College,

17 United States

18

19 Corresponding Author:

20 Ruairidh Sawers

21 Unidad de Genómica Avanzada (LANGEBIO), Centro de Investigación y de Estudios 22 Avanzados del Instituto Politécnico Nacional, Irapuato, Guanajuato, Mexico

23 e-mail address: ruairidh.sawers@gmail.com

24

25

26

27 


\section{ABSTRACT}

29 Background. The spread of maize cultivation to the highlands of central Mexico was

30 accompanied by substantial introgression from the endemic wild teosinte Zea mays ssp.

31 mexicana, prompting the hypothesis that the transfer of beneficial variation facilitated local

32 adaptation.

33 Methods. We used whole-genome sequence data to map regions of Zea mays ssp. mexicana

34 introgression in three Mexican highland maize individuals. We generated a genetic linkage map

35 and performed Quantitative Trait Locus mapping in an $\mathrm{F}_{2}$ population derived from a cross

36 between lowland and highland maize individuals.

37 Results. Introgression regions ranged in size from several hundred base pairs to Megabase-scale

38 events. Gene density within introgression regions was comparable to the genome as a whole, and

39 over one thousand annotated genes were located within introgression events. Quantitative Trait

40 Locus mapping identified a small number of loci linked to traits characteristic of Mexican

41 highland maize.

42 Discussion. Although there was no strong evidence to associate quantitative trait loci with

43 regions of introgression, we nonetheless identified many Mexican highland alleles of

44 introgressed origin that carry potentially functional sequence variants. The impact of

45 introgression on stress tolerance and yield in the highland environment remains to be fully

46 characterized. 


\section{INTRODUCTION}

48 Maize (Zea mays ssp. mays) was domesticated in southwestern Mexico approximately 9, 000

49 years ago from an annual wild grass, the teosinte Zea mays ssp. parviglumis (Matsuoka et al.

50 2002; Piperno et al. 2009). Following domestication, maize dispersed across Mexico and

51 diversified to give rise to locally-adapted landrace varieties (Wellhausen et al. 1952; Sanchez G.

52 and Goodman 1992; Ruiz Corral et al. 2008; Perales and Golicher 2014). Cultivated maize

53 spread rapidly beyond the ancestral niche occupied by parviglumis (Piperno 2006; Merrill et al.

54 2009; Grobman et al. 2012), raising questions as to the origin and nature of the genetic variation

55 underlying adaptive phenotypic change. Within Mexico, the colonization of the highland Central

56 Plateau represents a clear example of niche expansion with respect to the parviglumis ancestor

57 (Piperno 2006). The Mexican highlands present a unique combination of environmental

58 challenges to maize cultivation: low temperatures necessitate planting early in the year in order

59 that plants might reach maturity, in turn risking exposing seedlings to frost and water deficit

60 before the onset of annual rains; throughout the growing season, low-temperature, high-levels of

61 UV radiation and hail storms pose further difficulties (Eagles and Lothrop 1994; Lafitte and

62 Edmeades 1997; Jiang et al. 1999; Mercer et al. 2008); the volcanic origin of the central highland

63 region, and the associated acidic nature of the soils, restricts the bioavailability of phosphorus

64 (Bayuelo-Jiménez and Ochoa-Cadavid 2014).

65 The first maize to be cultivated in the Mexican highlands encountered not only new

66 environmental challenges, but also the highland-adapted teosinte Zea mays ssp. mexicana

67 (hereafter, mexicana. Hufford et al. 2012a). Mexican highland maize and mexicana share

68 morphological traits (most obviously, pronounced stem pigmentation and pubescence) that are

69 rarely seen in parviglumis and lowland maize (Wellhausen et al. 1953; Wilkes 1976). This 
70 common morphology presented the first indication of introgression between mexicana and

71 maize, interpreted variously as the adoption of adaptive traits by maize or as mimicry by teosinte

72 to evade removal from cultivated fields (Wilkes 1972; Lauter et al. 2004). Subsequent molecular

73 studies have demonstrated shared ancestry between highland maize and mexicana (Doebley

74 1990; Matsuoka et al. 2002; van Heerwaarden et al. 2011; Hufford et al. 2013). Introgression

75 from mexicana to maize is more common than in the opposite direction, with mexicana

76 contributing around $20 \%$ of the genome of Mexican highland maize varieties (van Heerwaarden

77 et al. 2011; Hufford et al. 2013; Romero Navarro et al. 2017; Wang et al. 2017). The use of

78 increasing numbers of molecular markers and whole genome sequence datasets has allowed the

79 mapping of large-scale regions of introgression within Mexican highland maize genomes

80 (Hufford et al. 2013; Wang et al. 2017). A number of introgressed haplotypes are found at high

81 frequency in Mexican highland maize, while being rare or absent in lowland populations,

82 consistent with a possible role in local adaptation (Hufford et al. 2013; Takuno et al. 2015;

83 Romero Navarro et al. 2017; Wang et al. 2017).

84 Introgression has been proposed as a mechanism whereby invasive populations can

85 rapidly acquire the genetic variation necessary to adapt to local environmental challenges

86 (Hedrick 2013; Martin and Jiggins 2017). For example, introgression of genes from Heliconius

87 melpomene butterflies to $H$. timareta has been linked to the acquisition of mimetic red wing

88 patterns (Pardo-Diaz et al. 2012). Similarly, it has been suggested that the adaptation of

89 Arabidopsis arenosa to serpentine soils was facilitated by introgression from the related species

90 A. lyrata (Arnold et al. 2016). In cultivated barley, introgression from wild relatives appears to

91 have aided expansion and adaptation (Poets et al. 2015). The expansion of weedy Helianthus

92 annuиs into certain regions of Texas was driven by admixture with the wild relative $H$. debilis, 
93 promoting increased herbivore resistance (Whitney et al. 2006, 2015). Introgression from crops

94 to their wild-relatives has also been documented, directly enhancing vigor (Gutierrez et al. 2011),

95 or promoting persistence of weedy forms in cultivated fields through mimicry (Chen et al. 2004;

96 Xia et al. 2011).

$97 \quad$ The fate of any given locus following hybridization will depend not only on the adaptive

98 value of its associated variants but also the local genomic landscape in terms of recombination

99 rates and the nature of linked genes (Martin and Jiggins 2017). For example, studies in mice and

100 humans have found weaker signals of introgression in areas of the genome where gene density is

101 high and/or the recombination rate is low (Sankararaman et al. 2014; Janoušek et al. 2015;

102 Sankararaman et al. 2016; Martin and Jiggins 2017). In the context of crop plants, the potential

103 benefits of introgression from wild relatives with respect to local adaptation or stress tolerance

104 may be offset by decreased agronomic value as a result of linked pre-domestication gene content.

105 It has been hypothesized that introgression will be facilitated by high local levels of

106 recombination, allowing beneficial or neutral alleles to readily recombine away from undesirable

107 variants (Barton and Bengtsson 1986; Martin and Jiggins 2017). Nonetheless, previous reports

108 have described a number of Megabase-scale introgression events that have been transferred from

109 mexicana to maize, associated with regions of low recombination in pericentromeric regions or

110 chromosomal inversions (Hufford et al. 2013; Wang et al. 2017). If such large scale events are to

111 be maintained by positive selection, the net effect of many hundreds of wild alleles must be

112 beneficial. Although a low rate of recombination makes it hard to break linkage-drag, the flipside

113 may be to promote introgression by holding together groups of beneficial alleles that collectively

114 constitute an adaptive haplotype (Kirkpatrick and Barton 2006; Twyford and Friedman 2015;

115 Marques 2017). 
117 Mexican highland maize individuals. Introgression events were characterized with respect to

118 their size, gene content and variation. In addition, we generated a linkage map to estimate local

119 recombination rate. To assess the impact of gene flow on plant morphology and phenology, we

120 mapped QTL for a number of traits in an $\mathrm{F}_{2}$ mapping population and compared their location to

121 the introgression map.

122

123 MATERIALS AND METHODS

124 Plant material

125 Sequence data reported here was generated from two outbred individuals of accession Mexi5 of 126 the landrace Palomero Toluqueño (PT; collected near the city of Toluca, Mexico state at 19.29N, $127-99.57 \mathrm{~W}, 2,597$ masl), obtained from the collection of the International Center for Maize and 128 Wheat Improvement (CIMMyT) seed bank, and one outbred individual of accession TC313 of 129 landrace Mushito de Michoacán (MM; collected south of Pátzcuaro, Michoacán at 19.31N, 130 101.68W, 2271 masl), from the collection of Alfredo Carrera, Universidad Autónoma Chapingo, 131 Michoacán. Samples for sequencing were collected from mature field grown plants RS16-1032.6 132 (PT1), RS16-1032.9 (PT2) and RS13-1261.1 (MM). Individual PT1 was crossed as male to a 133 partially inbred stock derived from the Mexican landrace Reventador (RV; an S6 derivative of 134 accession Nay15, INIFAP. Bukowski et al. 2018), and a single individual of the resulting $\mathrm{F}_{1}$ 135 stock self-pollinated to generate an $\mathrm{F}_{2}$ family. A total of $170 \mathrm{RV} \times \mathrm{PT} 1 \mathrm{~F}_{2}$ individuals were 136 evaluated in a lowland field site (Valle de Banderas, Nayarit. Winter cycle 2017) and genotyped 137 to generate a genetic linkage map and perform QTL mapping (see below). 
139 Whole genome sequencing

140 Total genomic DNA was extracted by LANGEBIO-CINVESTAV Genomic Services

141 (http://www.langebio.cinvestav.mx/?pag=458). Whole genome sequencing was performed by

142 NGX-Bio (San Francisco, California, USA. 94107) using the Illumina HiSeq 3000/4000

143 platform, using HiSeq 4000 SBS chemistry to generate 150 bp paired-end reads. A total of 85.5,

144 87.7, and 144.7 Gb of sequence was generated for PT1, PT2, and MM1, respectively. Genome

145 sequence data is available from National Center for Biotechnology Information (NCBI)

146 Sequence Read Archive (SRA) database (PRJNA511379).

147

148 Public sequence data

149 Additional whole genome sequence data for the lowland maize landraces Nal Tel (

150 RIMMA0703) and Zapalote Chico (RIMMA0733) was taken from Wang et al., 2017 (NCBI

151 SRA SRP065483), and an extra lowland sequence (BKN022), mexicana (TIL08 and TIL25)

152 Tripsacum (TDD39103) and parviglumis (TIL01, TIL05, TIL10) from (Bukowski et al. 2018)

153 (/iplant/home/shared/panzea/hapmap3/bam). Genome sequence was obtained in bam format

154 aligned to the B73 reference genome v3 using BWA mem (BWA v.0.7.12. Li 2013).

155

156 Pre-processing of whole genome sequence data

157 The PT1, PT2 and MM1 sequence was processed using Trimmomatic v.0.32 (Bolger et al.

158 2014), set for pair-end data with the following parameters: LEADING: 3 TRAILING: 3

159 SLIDINGWINDOW: 4:15 MINLEN: 36. The resulting trimmed sequences, both paired and

160 single end, were mapped against the B73 reference genome v3 using BWA v.0.7.12 (Li. 2013),

161 under the default settings, using the -M option for Picard compatibility. The resulting sam 
162 output was sorted, and converted to bam format using Picard tools v.2.4.1

163 (http://broadinstitute.github.io/picard). Single-end and pair-end ordered bam files for each

164 individual were merged using samtools v.1.3.1 (Li et al. 2009), and duplicated molecules

165 removed with Picard tools using default parameters, with the flag

166 REMOVE_DUPLICATES=true. The files were indexed using Picard Tools and indel

167 realignment carried out with the Genome Analysis Toolkit (GATK) v.3.5.0 (McKenna et al.

168 2010). Publicly available lowland maize, mexicana and Tripsacum bam format sequences were

169 processed using the same pipeline from the removal of duplicate molecules onwards.

170

\section{Calculation of $D$ and fd}

172 Genotype likelihoods (GL) were calculated using ANGSD v.0.912 (Korneliussen et al. 2014)

173 with the following parameters: -GL 1 -remove_bads 1 -nThreads 8 -doGlf 3 -doMajorMinor 1 -

174 doMaf 1 -SNP_pval 1e-6 -minInd 2 -minMapQ 30 -minQ 20. Inbreeding values were calculated

175 for each individual with ngsF v1.2.0 (Vieira et al. 2013), using the script ngsF.sh with the

176 following parameters: --n_threads 20 --n_ind 9 --min_epsilon 1 e-6 --glf $<$ GL calculated with

177 ANGSD > --n_sites < number of called SNPs>, giving the following values: RIMMA0703, 0.22;

178 RIMMA0733, 0.30; TIL25, 0.59; TIL08, 0.66; TDD39103, 0.64: BKN022, 0.69: PT1, 0.00084;

179 PT2, 0.00156; MM, 0.00042; TIL10, 0.49; TIL05, 0.56; TIL01, 0.48.Inbreeding coefficients

180 were used in a ANGSD SNP calling to account for deviations of the HWE using the following

181 parameters: -SNP_pval 1e-6 -GL 1 -doMajorMinor 1 -doMaf 1 -rf -remove_bads 1 -minMapQ

18230 -minQ 20 -minInd 4 -doGeno 4 -doPost 1 -postCutoff 0.95 -indF < inbreedingValues $>$.

183 Allele frequencies were used to calculate $f_{d}$ and D using the script ABBA_BABA.v1.pl (Owens

184 et al. 2016), based on the tree (((P 1 , P 2$),$ P 3 ), O), where the P1 position was the three 
185 lowland genomes BKN022, RIMMA0703 and RIMMA0733, P2 was the three highland 186 genomes PT1, PT2 and MM, P3 was the two teosinte mexicana genomes TIL08 and TIL25, and

187 O was the Tripsacum genome TDD39103. From this analysis, we calculated the average value of $188 \mathrm{D}$ across the genome, along with an associated $\mathrm{p}$ value estimated from the distribution of $\mathrm{D}$ 189 values calculated in non-overlapping windows of $5 \mathrm{Mb}$ across the genome 190 (ABBA_out_blocker.pl; Jacknife_ABBA_pipe.R; ABBA_pvalue.R. Owens et al. 2016). To 191 calculate $\mathrm{D}$ at the level of individual chromosomes, we used non-overlapping windows of $1 \mathrm{Mb}$.

192 To map introgression within the genome, a custom $\mathrm{R}$ script was used to calculate $f_{d}$ in non193 overlapping windows of 50 informative (ABBA/BABA) sites, based on the ABBA_BABA.v1.pl 194 output. We considered the sets of the top $1 \%$ and $10 \%$ scoring windows as positive for 195 introgression (Table S1, S2). Raw $f_{d}$ output is provided in Table S3. We also generated a null 196 data set, substituting South American for Mexican maize (Table S4). The average of $f_{d}$ at the 197 whole genome was taken as the proportion of introgression. The location of gene models in 198 introgression regions is listed in Table S5.

199

200 Genotypic analysis of a RV x PT F family and construction of genetic linkage map

201 Total genomic DNA was extracted from $170 \mathrm{~F}_{2}$ individuals derived from the cross of RV x PT1 202 using the Qiagen $(\mathrm{GmBH})$ DNeasy Plant Mini kit DNA extraction kit, according to the 203 manufacturer's instructions. Samples were analysed by the International Center for Maize and 204 Wheat Improvement (CIMMyT) using the DaRT platform 205 (http://seedsofdiscovery.org/es/catalogo/saga-servicio-de-analisis-genetico-para-la-agricultura/.

206 (Sansaloni et al. 2011). Using tag sequences of $\sim 65 \mathrm{bp}$, a total of 26,727 SNPs were identified, 207 with $<50 \%$ missing data. Tags were anchored to physical positions in the B73 v3 reference 
208 genome using BLAST (Altschul 1990), under the following parameters: $\min \%$ for each base $=$ $2093, \max \%$ for each base $=60$, e-value $=5 \mathrm{e}^{-10}$, $\max$ hits per sequence $=10$, percent overlap $=90$, 210 percent identity $=90$. Tags aligning to multiple positions and those that contained multiple 211 SNPs, were discarded, as were tags derived from heterozygous sites for which only one allele 212 could be aligned under the defined parameters, and sets of two or more tags that aligned to a 213 common position. The exact position for each SNP was calculated on the basis of the position of 214 the SNP within the tag and the position of the alignment of the tag against B73. The resulting set 215 of 10,323 SNPs were transformed to hapmap format, and filtered to identify segregating sites 216 (allele frequency $>0.2$ and $<0.8$ ), thinned to minimum spacing of $1 \mathrm{~kb}$, and transformed to $\mathrm{ABH}$ 217 format (A: PT; B: RV) using TASSEL v5.0 (Bradbury et al. 2007). The data were inspected 218 visually using ABHgenotypeR v1.0.1 (Furuta et al. 2017), and passed to the ABHgenotypeR 219 pipeline to impute missing data, corrected for under-called heterozygous sites, and corrected for 220 single interspersed alleles using a maximum haplotype length of 6 . The proportion of missing 221 sites dropped from 0.57 to 0.02 following imputation. The final proportion of sites was $24.4 \%$ 222 A, $23.6 \%$ B, $52.0 \% \mathrm{H}$. Markers were assigned to linkage groups and ordered based on the B73 223 v3 physical map prior to estimation of the genetic map using R v3.4.0 (R Core Team 2014) with 224 R/QTL v1.41.6 (Broman et al. 2003), following the recommendations available at 225 http://www.rqtl.org/tutorials/geneticmaps.pdf. The marker set was reduced once more on the 226 basis of redundancy in the genetic map using the functions qtl::findDupMarkers and 227 qt1::drop.markers, resulting in a final set of 1, 166 SNPs that was passed to the function 228 qt1::est.map with the kosambi mapping function. Genetic and physical distances were extracted 229 per chromosome using qt1::pull.map. Local estimates of recombination rates (RR) $(\mathrm{cM} / \mathrm{Mb})$ were 230 obtained using R/MareyMap v1.3.4 (Rezvoy et al. 2007), fitting a cubic spline across each 
231 chromosome, using the parameters spar $=0.05$ and $\mathrm{df}=10$ (Table S6, S7). Markers that distorted

232 the monotonic increase of the fitted spline were removed by hand to avoid negative rates. The 233 genetic map of the Maize Nested Association Mapping Population was obtained from

234 MaizeGDB (Andorf et al. 2016) and physical positions were taken as the midpoint of genes 235 associated with the markers, with local estimates of RR calculated as described above.

\section{Functional annotation of sequence variants}

The SNPs obtained with ANGSD were converted to hapmap format using custom scripts, passed to TASSEL v5.2.43, and converted to vcf format, the reference allele at any given site being defined based on the B73 reference genome v3, set using bcftools v1.5. To perform functional annotation, the vef file was passed to SnpEff v4.3 (Cingolani et al. 2012; Table S8). A custom R script was used to select SNPs homozygous for the alternative allele in the three highland maize genomes. Population differentiation data for Mexican highland and lowland maize populations was taken from (Takuno et al. 2015). Maize gene annotation was taken from maize-GAMER (https://dill-picl.org/projects/gomap/maize-gamer/).

\section{QTL mapping of variation in morphological traits and flowering time}

248 The $170 \mathrm{~F}_{2} \mathrm{RV} x$ PT1 individuals used for the linkage mapping were grown to maturity in a 249 lowland winter nursery (Valle de Banderas, Nayarit, Mexico. 20.8 N, -105.2 W, 54 masl), and 250 evaluated for the following traits: plant height $(\mathrm{PH})$, ear height $(\mathrm{EH})$, stem pigment intensity 251 (INT), stem pigment extent (EXT), stem macrohair pattern (MPAT); stem macrohair density 252 (MDEN), tassel (male inflorescence) branch number (TBN), tassel length (TL) and days-to253 anthesis (DTA). INT was evaluated on a semi-quantitative scale form 0 - 4. EXT was scored as 
$2540 \%, 25 \%, 50 \%, 75 \%$ or $100 \%$. MAPT was scored as 0 (no stem macrohairs), 1 (marginal

255 macrohairs only), 2 (patchy macrohair production on the sheath) or 3 (uniform macrohair

256 production on the sheath). MDEN was scored semi-quantitatively from 0 to 4 . Other traits were

257 evaluated as described previously (Flint-Garcia et al. 2005). QTL mapping was conducted using

258 a single-scan in R/QTL (Broman et al. 2003), with the support of R/QTLtools (Lovell et al.

259 2018). Phenotypic data and the genetic map are provided as an R/QTL cross object in Table S9.

260

261 RESULTS

262 Introgression from mexicana is distributed throughout the genome of Mexican highland

263 maize

264 To characterize introgression from mexicana to Mexican highland maize, we generated whole

265 genome sequence data from two outbred individuals of the landrace Palomero Toluqueño (PT1

266 and PT2) and a single outbred individual of the landrace Mushito de Michoacán (MM1), yielding

267 a coverage of $\sim 40$ fold for PT1 and PT2, and $\sim 70$ fold for MM1 (Table S10). In total, we

268 identified 71,623,944 single nucleotide polymorphisms (SNPs) across the three individuals. To

269 estimate the extent of mexicana introgression, we calculated Patterson's $D$ statistic (Durand et al.

270 2011) and genome-wide $f_{d}$ (Martin et al. 2017). Briefly, working with genomic sequence from

271 highland and lowland maize, mexicana and the related grass Tripsacum (see Materials and

272 Methods), we identified those sites that were polymorphic between Tripsacum and mexicana,

273 and compared the frequency with which highland maize carried the mexicana allele and lowland

274 maize the Tripsacum allele (the "ABBA" pattern) to the frequency of the complementary case

275 (the "BABA" pattern) (Green et al. 2010). A total of 905,537 SNPs were characterized as

276 following either the ABBA or BABA pattern, and, therefore, to be informative for the analysis. 
277 Our analysis revealed strong evidence of shared ancestry between mexicana and our highland

278 maize samples (D, $Z$ score $>9.56$; Table 1$)$, with mexicana introgression estimated by $f_{d}$ to

279 account for $\sim 7 \%$ of the highland maize genomes.

280 To localize introgression within the genome, we calculated $f_{d}$ in non-overlapping

281 windows of 50 informative sites. We considered relatively high-scoring windows to be positive

282 for introgression, selecting the sets of the top $1 \%$ and top $10 \%$ outliers for further analysis.

283 Adjacent positive windows were concatenated, defining 80 ( $8.86 \mathrm{Mb}$ or $0.43 \%$ of the genome)

284 and 679 (101.98 Mb or $4.95 \%$ of the genome) introgression events for $1 \%$ and $10 \%$ sets,

285 respectively (Fig. 1; Tables S1, S2). In light of our genome-wide estimation of 7\% mexicana

286 ancestry, both the $1 \%$ and $10 \%$ sets appear to be conservative. Introgression events were

287 distributed across all ten chromosomes, although not uniformly, with chromosome (chr) 4

288 particularly enriched (Fig. 1A; Table 1). In the 1\% outlier set, 29 of a total of 80 events were

289 located on chr 4, representing $58 \%$ of the total introgressed DNA by size. For the $10 \%$ outlier

290 set, 90 of 679 events were located on chr 4, representing $24 \%$ of the total by size. Genomewide,

291 the size of introgression events in the $1 \%$ outlier set ranged from 0.53 to $630 \mathrm{~kb}$. The upper limit

292 was substantially increased in the $10 \%$ set, with events ranging from 0.34 to $4,700 \mathrm{~kb}$, indicating

293 that many of the windows between the first and tenth percentile were clustered in the genome. In

294 both $1 \%$ and $10 \%$ outlier sets, the majority (95\% in both cases) of the events were less than 0.5

$295 \mathrm{Mb}$ in size, with these small events also constituting the majority of the total physical

296 introgression size (Fig. 2B). Nine events were identified that were $>1 \mathrm{Mb}$ in size, all from the

$29710 \%$ outlier set. These included events that co-localized with previously reported Megabase-

298 scale introgression regions (Fig. 1A; Table S11; Hufford et al. 2013; Romero Navarro et al.

299 2017; Wang et al. 2017): the Inv4m inversion polymorphism on chr 4 (located at $169-180 \mathrm{Mb}$; 
300 represented as fifteen closely located events in our analysis), a region on chr 6 (located at 46 - 57

$301 \mathrm{Mb}$; four events in our analysis) and a region on chr 3 (located at $75-90 \mathrm{Mb}$; three events in our 302 analysis).

303 To assess the potential functional significance of mexicana introgression, we examined

304 the gene content of the introgression events on the basis of the B73 reference genome (Table S5).

305 While previously reported Megabase-scale regions harbor a large number of annotated genes, we 306 considered the possibility that smaller regions were largely distributed in gene-poor sections of

307 the genome, perhaps as remnants of historical gene flow, experiencing little purifying selection

308 as a result of limited functionality. Overall, the cumulative distribution of gene number as a

309 function of ordered physical size conformed with the expectation of genome-wide gene density,

310 with a total of 1, 380 genes (3.5\% of the tested genes) found inside the $10 \%$ outlier events (Fig.

311 1C; Table S5). There was no indication that small introgression events were gene-poor, and it

312 was at the higher end of the size spectrum that gene-density fell slightly below the genome wide

313 value, consistent with the location of many of the larger events in pericentromeric regions.

315 Large introgression events are located in regions of low genetic recombination

316 The most reproducible signals of introgression from mexicana to Mexican highland maize are

317 associated with Megabase-scale events that co-localize with putative chromosomal inversions

318 (e.g. regions on $\mathrm{Chr} 3$ and $\mathrm{Chr} 4$ reported here and previously by Hufford et al. 2013; Romero

319 Navarro et al. 2017; Wang et al. 2017), consistent with the hypothesis that a low local rate of

320 genetic recombination can favor introgression (Kirkpatrick and Barton 2006). Of course, it is

321 also clear that such large scale events are easier to detect. To characterize the recombination

322 landscape of the PT genome, we generated a genetic linkage map from the cross of PT1 and the 
323 lowland Mexican landrace Reventador (RV; partially inbred accession used in the $f_{d}$ analysis).

324 The total map length was $1,275 \mathrm{cM}$, with a global recombination rate (RR) of $0.61 \mathrm{cM} / \mathrm{Mb}$

325 (based on the size of the B73 v3 physical map). At the level of individual chromosomes, RR

326 ranged from 0.69 on chr 1 to 0.49 on chr 8 (Table 1). As is typical, local RR values were high in

327 the telomeric regions and low around the centromeres (Fig. 2A. Table S6). In addition, we

328 observed variation across the genome with clear recombination hot and cold spots (Fig. 2A). For

329 each introgression event, RR was estimated based on the midpoint location. The RR differed

330 depending on the size of the introgression events (Kruskal-Wallis test, $p<0.001$. Fig $2 \mathrm{~B}$ ): while

331 small $(<250 \mathrm{~kb})$ events were distributed across a range of $\mathrm{RR}$, large regions $(>250 \mathrm{~kb})$ were

332 constrained to regions where $\mathrm{RR}<0.5$ (Fig $2 \mathrm{~B})$, with the exception of one event on $\operatorname{chr} 3(\mathrm{RR}=$

$3330.58)$ and one on chr $4(R R=1.91)$, although, in both cases, $R R$ was reduced compared with

334 their surroundings (Tables S6, S7). Of the 32 events $>0.5 \mathrm{Mb}$ identified from the $10 \%$ outlier

335 set, 18 were located in pericentromeric regions (defined as the region for which $R R \preccurlyeq 0.2$

336 extending from the estimated position of the centromere. Fig. 2A; Table S12), suggesting that we

337 have more large introgression events at pericentromeric regions than expected $\left(\chi^{2}=7.73, \mathrm{df}=\right.$

$3381, \mathrm{p}$ value $=0.005)$, consistent with the idea that highland maize carry centromeric or

339 pericentromeric regions from mexicana (Hufford et al. 2013). We compared our map with the

340 maize Nested Association Mapping (NAM) population reference (McMullen et al. 2009), which

341 did not include highland maize material in its construction. We found that the non-

342 pericentromeric regions harboring large $(>0.5 \mathrm{Mb})$ introgression events in our analysis presented

343 lower local rates of recombination than the corresponding positions in the NAM map (paired-

344 sample Wilcoxon test, $\mathrm{p}$ value $<0.001$; Table S12), suggesting that these regions themselves

345 may be suppressing recombination. The strong signal of introgression across $\operatorname{Inv} 4 m$ coincided 
346 clearly with a region of low RR, consistent with the segregation of inverted and standard

347 haplotypes in our PT x RV cross (Fig. 3. Hufford et al. 2013; Romero Navarro et al. 2017; Wang 348 et al. 2017).

349

350

351

Introgression events contribute to the differentiation of Mexican highland and lowland maize

352

To better understand the importance of introgression in the differentiation of highland and lowland Mexican maize, we examined a previously published $\mathrm{F}_{\mathrm{ST}}$ data set (Takuno et al. 2015), comparing genes inside and outside of our introgression events (Table S5). For 409 genes reported to show significant differentiation (from a total of 21, 029 genes for which an $\mathrm{F}_{\text {st }}$ estimate was available), $62(15 \%)$ were located in the set of $10 \%$ outlier introgression events, an enrichment over the genome-wide expectation $\left(\chi^{2}=205, \mathrm{df}=1, \mathrm{p}\right.$ value $<0.001$. Table S13).

This trend was driven, in part, by the large number of high $\mathrm{F}_{\mathrm{ST}}$ genes within introgression events 359 on chr 4 (34 of the total of 62 high $\mathrm{F}_{\mathrm{ST}}$ genes within introgression), although the enrichment remained even after removal of $\operatorname{chr} 4$ from the data set $\left(\mathrm{X}^{2}=57, \mathrm{df}=1, \mathrm{p}\right.$-value $<0.001$. Table S14). Across the 21, 029 genes for which an estimate was available, the median $F_{\mathrm{ST}}$ value was significantly higher for 636 genes located in introgression regions than for the remaining 20, 393 genes (Wilcox test,, $\mathrm{p}$ value $<0.001$ ). When chromosomes were considered individually, chr 3 ,

4, 8 and 9 showed a significant $(\mathrm{p}<0.01)$ difference in $\mathrm{F}_{\mathrm{ST}}$ (Fig. 4A).

\section{Introgression events contain variation of potential significance for protein function}

To assess functional variation, we categorized the SNPs identified in genes on the basis of their possible impact on encoded proteins using SnpEff (Cingolani et al. 2012). Genes located in 
369 introgression events showed an excess of high $\left(\chi^{2}=35.03, \mathrm{df}=1, \mathrm{p}\right.$ value $<0.001$. Table S15)

370 and moderate $\left(\chi^{2}=222.72, \mathrm{df}=1, \mathrm{p}\right.$-value $<0.001$. Table S16) effects fixed in our sample of

371 three genomes (six alleles). In total, 40 of the 1, 380 genes in introgression events were

372 homozygous for the alternate allele at one of more high-effect SNPs across all three highland

373 maize individuals (45 SNPs in total; Table S8). An additional 502 genes were fixed for the

374 alternate allele at one or more moderate-effect SNPs (1, 740 SNPs in total; Table S8). We further

375 categorized fixed high- and moderate- effect SNPs with respect to the other samples in our

376 analysis (Fig. 4B. Table S8). The majority of SNPs in introgression regions fixed for the

377 alternate allele in our highland maize samples were also fixed for the alternate allele in mexicana

378 (1, 346 of 1, 785 SNPs). Of these, 61 highland-fixed SNPs (located in 40 genes) unambiguously

379 followed the "ABBA" pattern used initially for the selection of introgression regions (i.e. fixed

380 for the alternate allele in highland maize and mexicana; fixed for the reference allele in

381 Tripsacum, lowland maize, and, although not included in the earlier analysis, also parviglumis).

382 A further 168 highland-fixed SNPs (located in 96 genes) were not called in Tripcascum (and

383 therefore, were not used in our estimation $f_{d}$ ), but were fixed for the alternate allele in highland

384 and mexicana samples and fixed for the reference allele in lowland and parviglumis samples,

385 consistent with introgression. The largest category resulting from this grouping consisted of 193

386 SNPs (located in 104 genes) that were not called in Tripsacum, were fixed alternate in highland

387 and mexicana samples, and segregating in lowland and parviglumis samples. Such SNPs

388 differentiate highland and lowland individuals in both teosinte and maize, and their distribution

389 within putative introgression events is consistent with an introgressed origin. A total of 70

390 highland-fixed SNPs (located in 41 genes), including 48 in the $I n v 4 m$ region, were private to our

391 highland genomes. 
393 the list of genes in introgression events with the classical maize gene list, a curated set of 4, 908

394 well characterized genes (the "combined set" gene list was obtained from

395 www.maizegdb.org/gene center/gene and filtered for unique gene identifiers). Considering the

396 classical genes located in introgression regions as a whole, a diverse range of functions are

397 represented, many that are potentially significant to morphology or environmental responses

398 (Table 2). Intriguing examples include the $B x 8$ gene required for the biosynthesis of

399 benzoxazinoid defense compounds (Frey et al. 1997), the phosphorus homeostasis gene Phol;2a

400 (Salazar-Vidal et al. 2016), the flowering-time locus Gi2 (Mendoza et al. 2012), and various

401 genes related to phytohormone biosynthesis, ear morphology and grain development (Table 2).

402 These last include the genes Compact Plant2 (Ct2), Fasciated Ear3 (Fea3) and Tunicate (Tu1)

403 that play a role in the regulation of plant meristems (Han et al. 2012; Je et al. 2016; Wu et al.

404 2018; Han et al. 2012), the genes Nana Plantl (Na1) and Nana2-likel (Natll) involved in

405 brassinosteroid biosynthesis (Hartwig et al. 2011; Best et al. 2016), Aminocyclopropane

406 carboxylate oxidase20 (Acco20) involved in ethylene biosynthesis (Mira et al. 2016), and the

407 genes Dwarf8 (D8) and Kaurene oxidasel (Kol) that play a role in gibberellic acid signaling

408 (Peng et al. 1999).

409 To look at the possible implication of post-domestication gene flow during the early

410 development of cultivated maize, introgression events were compared with the location of

411 previously reported domestication and improvement genes (Hufford et al. 2012b). Of 420

412 reported domestication candidates present in the B73 v3 reference genome annotation (i.e. genes

413 showing a reduction in diversity and increased differentiation between teosinte and landrace

414 maize), 17 (3.6\%) were located in introgression events (based on 10\% outliers). Similarly, of 
415529 annotated improvement candidates (i.e. genes showing a reduction in diversity between 416 landrace maize and modern inbred lines), 22 (3.8\%) were located in introgression regions. For

417 both domestication and improvement candidates the proportion within introgression events 418 mirrored the genome-wide value of $3.5 \%$ (domestication: $\chi^{2}=0.2185, \mathrm{df}=1$, $\mathrm{p}$ value $=0.64$; 419 improvement: $\chi^{2}=0.48451, \mathrm{df}=1, \mathrm{p}$ value $=0.48$ ). As such, we see no evidence that these 420 candidates are refractory to introgression.

421

422

Introgression events on chromosome 9 co-localize with a previously-reported QTL for 423 sheath pubescence

424 One of the most striking morphological characteristics of Mexican highland maize is the 425 presence of pronounced stem pubescence (Fig. 5A. Wellhausen 1952). In a previous study, 426 evidence of mexicana introgression was identified on chr 9 (106.5 Mb - 125.5 Mb. Hufford et al. 427 2013), co-localizing with macrohairless 1 ( $m h l 1)$, a locus linked with production of macrohairs 428 on the adaxial surface of the leaf blade in inbred maize lines ( 115 Mb. Moose 2004$)$. We recovered a single introgression event in this region of chr 9 in our $1 \%$ outlier set, and a number 430 of events in our $10 \%$ outlier set (Table S1; S2). A previous experiment to map sheath pubescence 431 in a cross between parviglumis and mexicana identified a major effect QTL on the long-arm of $432 \operatorname{chr} 9$, consistent with the action of mexicana-specific neomorphic allele of $m h l 1$ extending the 433 production of macrohairs from leaf blade to sheath (Lauter et al. 2004). In a further study, using 434 recombinant inbred lines derived from the cross between B73 and PT, there was also evidence to 435 link a QTL in the mhll region to stem pubescence (Aguilar-Rangel, $\mathrm{PhD}$ Thesis, 2018). Here, we 436 attempted to map stem pubescence in the $\mathrm{F}_{2}$ progeny of our PT x RV cross. Upon evaluation, 437 however, we found that the majority of the $F_{2}$ plants (140 of 157) presented stem macrohairs 
438 (scored on a semi-quantitative scale). While this provided insufficient variation for successful

439 QTL mapping, it may indicate the action of multiple dominant-acting factors. We confirmed that

440 the lowland RV parent did not show stem pubescence. We anticipate that the use of inbred

441 material to reduce the confounding effects of dominance, along with fine-scaled quantitative

442 evaluation, would provide a better characterization of the genetic architecture of stem macrohair

443 production in the PT $x$ RV cross.

444

445 QTL peaks associated with morphological and flowering traits do not co-localize with 446 introgression events

447 In addition to stem pubescence, we evaluated the PT $x \mathrm{RV} \mathrm{F}_{2}$ population for a number of further 448 morphological and flowering time traits to explore any possible association with introgression.

449 QTL were identified associated with stem pigment intensity (INT), stem pigment extent (EXT), 450 tassel (male inflorescence) branch number (TBN), tassel length (TL) and days-to-anthesis (DTA. 451 Table 3). The QTL intervals themselves were large (typically, tens of Mbs), and, necessarily, 452 contained multiple introgression events. In no instance, however, did the marker closest to a 453 QTL peak fall directly within one of our introgression events (Fig. 5B, Table 3). Given the 454 limited resolution of our mapping, we looked for instances where we might identify a candidate 455 gene within a given QTL interval for the purpose of evaluating local introgression; two such 456 candidates are discussed below.

457 The qTBN-7 interval contains the candidate gene Ramosal (Ral. GRMZM2G003927.

$458 \mathrm{Chr}$ 7: $110 \mathrm{Mb}$ ). The Ral product has been characterized to restrict production of long-branches 459 in both the male and female inflorescence (Vollbrecht et al. 2005). When we examined the 460 window containing $R a 1$ in our analysis, we found no evidence of introgression $\left(f_{d}=0.20\right)$. This 
461 is perhaps not too surprising given that mexicana, although described to present lower TBN than 462 parviglumis (Doebley 1983), does not present the extreme reduction in tassel branching that is 463 characteristic of Mexican highland maize.

464 The stem pigment QTL qINT-2 and qPAT-2 overlap on chr 2, defining an interval that 465 contains the candidate gene $B 1$ (GRMZM2G172795. Chr 2: $19 \mathrm{Mb})$. The $B 1$ gene encodes a 466 basic helix-loop-helix transcription factor that regulates the tissue-specific biosynthesis of 467 anthocyanins (Goff et al. 1992; Sharma et al. 2011). In contrast to greatly reduced tassel 468 branching, stem pigmentation is a trait shared by Mexican highland maize and mexicana. 469 Furthermore, there is evidence that allelic variation at $B 1$ is linked to stem pigmentation 470 differences between parviglumis and mexicana (Selinger and Chandler 1999; Lauter et al. 2004).

471 Nonetheless, inspection of the window containing $B 1$ in our analysis found no evidence of 472 introgression $(\mathrm{fd}=0.22)$, indicating that although variation at $B 1$ may drive stem pigmentation in 473 both mexicana and Mexican highland maize, the underlying alleles may have independent 474 origins.

475

476 DISCUSSION

477 Study of a number of crops has begun to indicate the significance of post-domestication gene 478 flow during the diversification and spread of cultivated varieties (Hufford et al. 2013; Poets et al. 479 2015; Bredeson et al. 2016; Rendón-Anaya et al. 2017). In line with previous reports (Hufford et 480 al. 2013; Wang et al. 2017), we have detected significant genome-wide introgression from 481 mexicana to Mexican highland maize. We estimated genome-wide introgression at $\sim 7 \%$, and we 482 mapped specific introgression events constituting $\sim 5$ of the total physical space. Our values 483 are somewhat lower than other estimates, that have ranged up to 20\% (Matsuoka et al. 2002; 
484 Hufford et al. 2013; Wang et al. 2017), reflecting the conservative criteria we employed, and, 485 potentially, the result of differences among the individuals in our sampling. Specifically, the 486 differing sources of PT and MM samples might be reflected in distinct patterns of introgression.

487 Similarly, we do not distinguish between introgression proceeding or contemporary with the 488 early diversification of the Mexican highland landrace group, and later events that might be 489 restricted to specific populations or races. Our analysis will largely have identified events that 490 are shared between PT and MM samples, consistent with both high frequency in contemporary

491 492 493 494 495 496 497 498 499 500 501 502 503 504 505 506 populations, and an origin early in the development of the Mexican highland group.

Previous reports of mexicana introgression to Mexican highland maize have focused on Mb-scale regions, events also recovered in our analysis. In addition, we also identified large numbers of small $(<500 \mathrm{~kb})$ events, that, collectively, constituted the bulk of the total introgression. Introgression events presented a gene-density equivalent to the genome as a whole, contrary to the hypothesis that they were harbored in gene-poor regions, possibly remnants of historical gene-flow with little functional significance. Nonetheless, 262 events $(\sim 10 \%$ of the total introgression by size), with an average size of $\sim 37 \mathrm{~kb}$, did not contain any annotated genes. A further 162 events contained only a single annotated gene. Small, single gene events, presumably the result of recombination following historical hybridization, would not be impacted by the negative effects of linked deleterious alleles, nor would they participate in hitchhiking through linkage to beneficial variants (Barton and Bengtsson 1986; Kirkpatrick and Barton 2006). As such, the persistence of single-gene introgression events would be predicted to reflect directly the fitness effects of associated allelic variants. Across all introgression events, we identified a number of genes that have previously been demonstrated to play major roles in maize development and growth, including well-characterized hormone-signaling genes.

Peer) reviewing PDF | (2019:01:34192:1:2:NEW 11 Mar 2019) 
507 Variation at loci related to phytohormone signalling has the potential to trigger pleiotropic

508 effects, impacting, for example, flowering time, morphology and stress tolerance. Indeed, the

509 capacity to retune simultaneously multiple aspects of plant morphology, phenology and stress

510 biology make hormone pathways compelling candidates as drivers of a collective adaptive

511 syndrome. Gene-level analyses were conducted on the basis of the B73 genome annotation.

512 Given the extensive copy-number variation known to be present in maize, it will be interesting to

513 re-evaluate introgression gene content when further genome assemblies become available for

514 landrace maize and maize wild-relatives.

515 Among the genes identified to be in introgression events, we recovered previously

516 characterized domestication and improvement candidates, at a rate equivalent to that observed

517 genome-wide. This observation somewhat contradicts an earlier report finding that regions of

518 introgression from mexicana to maize harbored fewer domestication candidates, while regions

519 resistant to such introgression were enriched for domestication candidates (Hufford et al. 2013).

520 It may be significant that we employed a greater number of markers than were used in the

521 previous report, and identified a larger number of small events. All the domestication candidates

522 we identified in introgression regions were in events $<775 \mathrm{~kb}$ in size (although four candidates

523 were located in small events co-localizing with the $I n v 4 m$ region).

524 Although many SNPs with potential functional relevance were identified in well-

525 supported gene models, we were unable to link introgression to the phenotypic traits we

526 evaluated. In the case of stem pubescence, we did not observe sufficient variation to permit QTL

527 mapping. Nonetheless, we did identify introgression events in the mhll region of chr 9, that has

528 been previously linked with stem pubescence in both mexicana and Mexican highland maize in

529 other studies (Lauter et al. 2004; Aguilar-Rangel, PhD Thesis, 2018). For stem pigmentation and 
530 tassel branch number, we mapped large-effect QTL that co-localized with high-confidence

531 candidate genes. The Ral candidate has also been linked to tassel branch number variation in a

532 maize $\mathrm{x}$ parviglumis population, the parviglumis allele increasing branching three-fold with

533 respect to the maize allele (Xu et al. 2017). PT is characterized by greatly reduced tassel

534 branching (often the tassel is a single, unbranched spike), consistent with a gain of Ral function

535 with respect to typical maize varieties, and reminiscent of the phenotype seen in maize liguleless 536 and unbranched mutants (Wellhausen 1952; Walsh and Freeling 1999; Chuck et al. 2014). As

537 such, we can hypothesize an allelic series of increasing Ral function from parviglumis, through

538 lowland maize, to Mexican highland maize. With respect to stem pubescence, a number of

539 functional variants of $B 1$ have been described, and differences in stem pigmentation linked to

540 transposon insertion in the region upstream of B1 (Radicella et al. 1992; Selinger and Chandler

541 1999; Selinger and Chandler 2001). Significantly, two previously characterized $B 1$ alleles from

542 mexicana were reported to present a different upstream structure to an allele from the Mexican

543 highland landrace Cacahuacintle (Selinger and Chandler 1999). Although the resolution of our

544 mapping limited broader conclusions concerning the impact of introgression, in $R a 1$ and $B 1$ we

545 have identified compelling candidates linked to large-effects in two of the most characteristic

546 morphological traits of Mexican highland maize. The fact that we see no evidence for

547 introgression at either Ral or $B 1$ may suggest that founder populations in the Mexican highlands

548 contained sufficient standing genetic diversity for these characteristic traits to arise without

549 recourse to gene flow. It is interesting to note that stem pigmentation is also prevalent in the

550 demographically distinct maize races of highland South America, where introgression from

551 mexicana is considered to be absent (Wellhausen, 1957; Wang et al., 2017).

552 Notwithstanding the results of our QTL analysis, the extent of mexicana introgression, 
553 and the number of variants identified, argues for a functional impact. The $I n v 4 m$ region has

554 previously been linked to flowering time in a large-scale association analysis (Romero Navarro

555 et al. 2017). The apparent discrepancy with respect to our observations may reflect the fact that

556 the evaluation was carried out in a lowland environment, or result from epistatic interactions that

557 we were not capable of detecting in our experiment. Indeed, it may well be that the broader

558 phenotypic effects associated with introgression are conditional on growth at high elevation, 559 acting in the modification of major QTL, in responses to biotic and abiotic stress, and in subtle, 560 but significant, contributions to yield and harvest quality traits.

561

562 CONCLUSION

563 We detected significant genome-wide introgression from mexicana to Mexican highland maize.

564 Employing conservative criteria, we mapped specific introgression events within the genome, 565 constituting $\sim 5 \%$ of the total physical space. Introgression events presented a gene-density 566 equivalent to the genome as a whole, and contained a significant number of genes that have 567 previously been demonstrated to play major roles in maize development and growth. Although 568 potential functional variants were identified, we were unable to link introgression to phenotypic 569 traits. While it is possible that that founder populations in the Mexican highlands contained 570 sufficient standing genetic diversity to support the adoption of the basic morphology and 571 phenology characteristic of modern highland varieties, the extent of mexicana introgression, and

572 the number of variants identified, nonetheless argues for a functional impact. We suggest that

573 this impact might yet be identified in modification of major QTL, in responses to biotic and

574 abiotic stress, and in contributions to yield and harvest quality traits under highland conditions. 575 
576

577

578

579

580

581

582

583

584

585

586

587

588

589

590

591

592

593

594

595

596

597

598

599

600

601

602

603

604

605

606

607

608

609

\section{ACKNOWLEDGEMENTS}

We thank Sherry Flint-Garcia and Susan Melia-Hancock for assistance with the collection of phenotypic data. We thank Ana-Laura Alonso Nieves for assistance with photography. Maize gene annotations were kindly compiled by Ricardo Chavez Montes.

\section{REFERENCES}

Aguilar-Rangel R (2018) The role of introgression from teosinte (Zea mays ssp. mexicana) in the adaptation of maize to the highlands of Mexico. PhD Thesis.

Altschul S (1990) Basic local alignment search tool. J Mol Biol 215: 403-410

Andorf CM, Cannon EK, Portwood JL 2nd, Gardiner JM, Harper LC, Schaeffer ML, Braun BL, Campbell DA, Vinnakota AG, Sribalusu VV, Huerta M, Cho KT, Wimalanathan K, Richter JD, Mauch ED, Rao BS, Birkett SM, Sen TZ, Lawrence-Dill CJ (2016) MaizeGDB update: new tools, data and interface for the maize model organism database. Nucleic Acids Res 44: D1195201

Arnold BJ, Lahner B, DaCosta JM, Weisman CM, Hollister JD, Salt DE, Bomblies K, Yant L (2016) Borrowed alleles and convergence in serpentine adaptation. Proc Natl Acad Sci U S A 113: 8320-8325

Barton N, Bengtsson BO (1986) The barrier to genetic exchange between hybridising populations. Heredity 57: 357-376

Bayuelo-Jiménez JS, Ochoa-Cadavid I (2014) Phosphorus acquisition and internal utilization efficiency among maize landraces from the central Mexican highlands. Field Crops Res 156: $123-134$

Best NB, Hartwig T, Budka J, Fujioka S, Johal G, Schulz B, Dilkes BP (2016) nana plant2 encodes a maize ortholog of the Arabidopsis brassinosteroid biosynthesis gene DWARF1, identifying developmental interactions between brassinosteroids and gibberellins. Plant Physiol 171: 2633-2647

Bredeson JV, Lyons JB, Prochnik SE, Albert Wu G, Ha CM, Edsinger-Gonzales E, Grimwood J, Schmutz J, Rabbi IY, Egesi C, Nauluvula P, Lebot V, Ndunguru J, Mkamilo G, Bart RS, Setter TL, Gleadow RM, Kulakow P, Ferguson ME, Rounsley S, Rokhsar DS (2016) Sequencing wild and cultivated cassava and related species reveals extensive interspecific hybridization and genetic diversity. Nat Biotechnol 34: 562-570

Bolger AM, Lohse M, Usadel B (2014) Trimmomatic: a flexible trimmer for Illumina sequence data. Bioinformatics 30: 2114-2120 
610 Bradbury PJ, Zhang Z, Kroon DE, Casstevens TM, Ramdoss Y, Buckler ES (2007) TASSEL: 611 software for association mapping of complex traits in diverse samples. Bioinformatics 23:

$612 \quad 2633-2635$

613 Broman KW, Wu H, Sen S, Churchill GA (2003) R/qtl: QTL mapping in experimental crosses.

614 Bioinformatics 19: 889-890

615 Bukowski R, Guo X, Lu Y, Zou C, He B, Rong Z, Wang B, Xu D, Yang B, Xie C, Fan L, Gao S, $616 \mathrm{Xu}$ X, Zhang G, Li Y, Jiao Y, Doebley JF, Ross-Ibarra J, Lorant A, Buffalo V, Romay MC, 617 Buckler ES, Ware D, Lai J, Sun Q, Xu Y (2018) Construction of the third-generation Zea mays 618 haplotype map. Gigascience 7: 1-12

619 Chen LJ, Lee DS, Song ZP, Suh HS, Lu B-R (2004) Gene flow from cultivated rice (Oryza 620 sativa) to its weedy and wild relatives. Ann Bot 93: 67-73

621 Chuck GS, Brown PJ, Meeley R, Hake S (2014) Maize SBP-box transcription factors 622 unbranched 2 and unbranched 3 affect yield traits by regulating the rate of lateral primordia 623 initiation. Proc Natl Acad Sci U S A 111: 18775-18780

624 Cingolani P, Platts A, Wang LL, Coon M, Nguyen T, Wang L, Land SJ, Lu X, Ruden DM 625 (2012) A program for annotating and predicting the effects of single nucleotide polymorphisms, 626 SnpEff: SNPs in the genome of Drosophila melanogaster strain w1118; iso-2; iso-3. Fly 6: 8062792

628 Doebley J (1990) Molecular evidence for gene flow among Zea species. Bioscience 40: 443-448

629

630

631

632

633

634

635

636

637

638

639

640

641

642

643

644 Green RE, Krause J, Briggs AW, Maricic T, Stenzel U, Kircher M, Patterson N, Li H, Zhai W,

Doebley JF (1983) The maize and teosinte male inflorescence: a numerical taxonomic study. Ann Mo Bot Gard 70: 32

Eagles HA, Lothrop JE (1994) Highland maize from central Mexico - its origin, characteristics, and use in breeding programs. Crop Sci 34: 11

Flint-Garcia SA, Thuillet A-C, Yu J, Pressoir G, Romero SM, Mitchell SE, Doebley J, Kresovich S, Goodman MM, Buckler ES (2005) Maize association population: a high-resolution platform for quantitative trait locus dissection. Plant J 44: 1054-1064

Frey M, Chomet P, Glawischnig E, Stettner C, Grün S, Winklmair A, Eisenreich W, Bacher A, Meeley RB, Briggs SP, Simcox K, Gierl A (1997) Analysis of a chemical plant defense mechanism in grasses. Science 277: 696-699

Furuta T, Ashikari M, Jena KK, Doi K, Reuscher S (2017) Adapting genotyping-by-sequencing for rice F2 populations. G3 7: 881-893

Goff SA, Cone KC, Chandler VL (1992) Functional analysis of the transcriptional activator encoded by the maize $B$ gene: evidence for a direct functional interaction between two classes of regulatory proteins. Genes Dev 6: 864-875 
645 Fritz MH, Hansen NF, Durand EY, Malaspinas AS, Jensen JD, Marques-Bonet T, Alkan C, 646 Prüfer K, Meyer M, Burbano HA, Good JM, Schultz R, Aximu-Petri A, Butthof A, Höber B, 647 Höffner B, Siegemund M, Weihmann A, Nusbaum C, Lander ES, Russ C, Novod N, Affourtit J, 648 Egholm M, Verna C, Rudan P, Brajkovic D, Kucan Ž, Gušic I, Doronichev VB, Golovanova LV, 649 Lalueza-Fox C, de la Rasilla M, Fortea J, Rosas A, Schmitz RW, Johnson PLF, Eichler EE, 650 Falush D, Birney E, Mullikin JC, Slatkin M, Nielsen R, Kelso J, Lachmann M, Reich D, Pääbo S 651 (2010) A draft sequence of the Neandertal genome. Science 328:710-722

652 Grobman A, Bonavia D, Dillehay TD, Piperno DR, Iriarte J, Holst I (2012) Preceramic maize 653 from Paredones and Huaca Prieta, Peru. Proc Natl Acad Sci U S A 109: 1755-1759

654 Gutierrez A, Cantamutto M, Poverene M (2011) Persistence of sunflower crop traits and fitness 655

656 657

658

659

660

661

662

663

664

665

666

667

668

669

670

671

672

673

674

675

676

677

678

679

680

681 in Helianthus petiolaris populations. Plant Biol 13: 821-830

Han J-J, -J. Han J, Jackson D, Martienssen R (2012) Pod corn is caused by rearrangement at the Tunicatel locus. Plant Cell 24: 2733-2744

Hartwig T, Chuck GS, Fujioka S, Klempien A, Weizbauer R, Potluri DPV, Choe S, Johal GS, Schulz B (2011) Brassinosteroid control of sex determination in maize. Proc Natl Acad Sci U S A 108: 19814-19819

Hedrick PW (2013) Adaptive introgression in animals: examples and comparison to new mutation and standing variation as sources of adaptive variation. Mol Ecol 22: 4606-4618

van Heerwaarden J, Doebley J, Briggs WH, Glaubitz JC, Goodman MM, de Jesus Sanchez Gonzalez J, Ross-Ibarra J (2011) Genetic signals of origin, spread, and introgression in a large sample of maize landraces. Proc Natl Acad Sci U S A 108: 1088-1092

Hufford MB, Lubinksy P, Pyhäjärvi T, Devengenzo MT, Ellstrand NC, Ross-Ibarra J (2013) The genomic signature of crop-wild introgression in maize. PLoS Genet 9: e1003477

Hufford MB, Martínez-Meyer E, Gaut BS, Eguiarte LE, Tenaillon MI (2012a) Inferences from the historical distribution of wild and domesticated maize provide ecological and evolutionary insight. PLoS One 7: e47659

Hufford MB, Xu X, van Heerwaarden J, Pyhäjärvi T, Chia J-M, Cartwright RA, Elshire RJ, Glaubitz JC, Guill KE, Kaeppler SM, Lai J, Morrell PL, Shannon LM, Song C, Springer NM, Swanson-Wagner RA, Tiffin P, Wang J, Zhang G, Doebley J, McMullen MD, Ware D, Buckler ES, Yang S, Ross-Ibarra J (2012b) Comparative population genomics of maize domestication and improvement. Nat Genet 44: 808-811

Janoušek V, Munclinger P, Wang L, Teeter KC, Tucker PK (2015) Functional organization of the genome may shape the species boundary in the house mouse. Mol Biol Evol 32: 1208-1220

Je BI, Gruel J, Lee YK, Bommert P, Arevalo ED, Eveland AL, Wu Q, Goldshmidt A, Meeley R, Bartlett M, Komatsu M, Sakai H, Jönsson H, Jackson D (2016) Signaling from maize organ primordia via FASCIATED EAR3 regulates stem cell proliferation and yield traits. Nat Genet 48: 785-791 
682 Jiang C, Edmeades GO, Armstead I, Lafitte HR, Hayward MD, Hoisington D (1999) Genetic

683 analysis of adaptation differences between highland and lowland tropical maize using molecular 684 markers. Theor Appl Genet 99: 1106-1119

685 Kirkpatrick M, Barton N (2006) Chromosome inversions, local adaptation and speciation.

686 Genetics 173: 419-434

687 Korneliussen TS, Albrechtsen A, Nielsen R (2014) ANGSD: Analysis of Next Generation 688 Sequencing Data. BMC Bioinformatics 15: 356

689 Lafitte HR, Edmeades GO (1997) Temperature effects on radiation use and biomass partitioning 690 in diverse tropical maize cultivars. Field Crops Res 49: 231-247

691 Lauter N, Gustus C, Westerbergh A, Doebley J (2004) The inheritance and evolution of leaf 692 pigmentation and pubescence in teosinte. Genetics 167: 1949-1959

693 Li H, Handsaker B, Wysoker A, Fennell T, Ruan J, Homer N, Marth G, Abecasis G, Durbin R, 6941000 Genome Project Data Processing Subgroup (2009) The Sequence Alignment/Map format 695 and SAMtools. Bioinformatics 25: 2078-2079

$696 \mathrm{Li}, \mathrm{H}$. Aligning sequence reads, clone sequences and assembly contigs with BWA-MEM (2013)

697 Preprint at http://arxiv.org/abs/1303.3997

698 Lovell JT, Jenkins J, Lowry DB, Mamidi S, Sreedasyam A, Weng X, Barry K, Bonnette J, 699 Campitelli B, Daum C, Gordon SP, Gould BA, Khasanova A, Lipzen A, MacQueen A, Palacio700 Mejía JD, Plott C, Shakirov EV, Shu S, Yoshinaga Y, Zane M, Kudrna D, Talag JD, Rokhsar D, 701 Grimwood J, Schmutz J, Juenger TE (2018) The genomic landscape of molecular responses to 702 natural drought stress in Panicum hallii. Nat Commun 9: 5213

703 Marques DA (2017) Adaptation despite gene flow? Low recombination helps. Mol Ecol 26:

$704 \quad 4361-4363$

705 Martin SH, Jiggins CD (2017) Interpreting the genomic landscape of introgression. Curr Opin 706 Genet Dev 47: 69-74

707 Matsuoka Y, Vigouroux Y, Goodman MM, Sanchez G J, Buckler E, Doebley J (2002) A single 708 domestication for maize shown by multilocus microsatellite genotyping. Proc Natl Acad Sci U 709 S A 99: 6080-6084

710 McKenna A, Hanna M, Banks E, Sivachenko A, Cibulskis K, Kernytsky A, Garimella K, 711 Altshuler D, Gabriel S, Daly M, DePristo MA (2010) The Genome Analysis Toolkit: a

712 MapReduce framework for analyzing next-generation DNA sequencing data. Genome Res 20:

713 1297-1303

714 McMullen MD, Kresovich S, Villeda HS, Bradbury P, Li H, Sun Q, Flint-Garcia S, Thornsberry 715 J, Acharya C, Bottoms C, Brown P, Browne C, Eller M, Guill K, Harjes C, Kroon D, Lepak N, 716 Mitchell SE, Peterson B, Pressoir G, Romero S, Oropeza Rosas M, Salvo S, Yates H, Hanson M, 717 Jones E, Smith S, Glaubitz JC, Goodman M, Ware D, Holland JB, Buckler ES (2009) Genetic 
718 properties of the maize nested association mapping population. Science 325: 737-740

719 Mercer K, Martínez-Vásquez Á, Perales HR (2008) Asymmetrical local adaptation of maize

720 landraces along an altitudinal gradient. Evol Appl 1: 489-500

721 Merrill WL, Hard RJ, Mabry JB, Fritz GJ, Adams KR, Roney JR, MacWilliams AC (2009) The

722 diffusion of maize to the southwestern United States and its impact. Proc Natl Acad Sci U S A

723 106: 21019-21026

724 Mira MM, Hill RD, Stasolla C (2016) Phytoglobins improve hypoxic root growth by alleviating 725 apical meristem cell death. Plant Physiol 172: 2044-2056

726

727

728

729

730

731

732

733

734

735

736

737

738

739

740

741

742

743

744

745

746

747

748

749

750

751

Moose SP (2004) The maize macrohairless 1 locus specifically promotes leaf blade macrohair initiation and responds to factors regulating leaf identity. Genetics 166: 1451-1461

Owens GL, Baute GJ, Rieseberg LH (2016) Revisiting a classic case of introgression: hybridization and gene flow in Californian sunflowers. Mol Ecol 25: 2630-2643

Pardo-Diaz C, Salazar C, Baxter SW, Merot C, Figueiredo-Ready W, Joron M, McMillan WO, Jiggins CD (2012) Adaptive introgression across species boundaries in Heliconius butterflies. PLoS Genet 8: e1002752

Peng J, Richards DE, Hartley NM, Murphy GP, Devos KM, Flintham JE, Beales J, Fish LJ, Worland AJ, Pelica F, Sudhakar D, Christou P, Snape JW, Gale MD, Harberd NP (1999) "Green revolution" genes encode mutant gibberellin response modulators. Nature 400: 256-261

Perales H, Golicher D (2014) Mapping the diversity of maize races in Mexico. PLoS One 9: e114657

Piperno DR (2006) Quaternary environmental history and agricultural impact on vegetation in central america. Ann Mo Bot Gard 93: 274-296

Piperno DR, Ranere AJ, Holst I, Iriarte J, Dickau R (2009) Starch grain and phytolith evidence for early ninth millennium B.P. maize from the Central Balsas River Valley, Mexico. Proc Natl Acad Sci U S A 106: 5019-5024

Poets AM, Fang Z, Clegg MT, Morrell PL (2015) Barley landraces are characterized by geographically heterogeneous genomic origins. Genome Biol 16: 173

Radicella JP, Brown D, Tolar LA, Chandler VL (1992) Allelic diversity of the maize $B$ regulatory gene: different leader and promoter sequences of two $B$ alleles determine distinct tissue specificities of anthocyanin production. Genes Dev 6: 2152-2164

R Core Team (2014) R: A language and environment for statistical computing. R Foundation for Statistical Computing

Rendón-Anaya M, Montero-Vargas JM, Saburido-Álvarez S, Vlasova A, Capella-Gutierrez S, Ordaz-Ortiz JJ, Aguilar OM, Vianello-Brondani RP, Santalla M, Delaye L, Gabaldón T, Gepts P, 
752 Winkler R, Guigó R, Delgado-Salinas A, Herrera-Estrella A. (2017) Genomic history of the

753 origin and domestication of common bean unveils its closest sister species. Genome Biol 18: 60

754 Rezvoy C, Charif D, Guéguen L, Marais GAB (2007) MareyMap: an R-based tool with

755 graphical interface for estimating recombination rates. Bioinformatics 23: 2188-2189

756 Romero Navarro JA, Willcox M, Burgueño J, Romay C, Swarts K, Trachsel S, Preciado E,

757 Terron A, Delgado HV, Vidal V, Ortega A, Banda AE, Montiel NO, Ortiz-Monasterio I, Vicente

758 FS, Espinoza AG, Atlin G, Wenzl P, Hearne S, Buckler ES (2017) A study of allelic diversity

759 underlying flowering-time adaptation in maize landraces. Nat Genet 49: 476-480

760 Ruiz Corral JA, Durán Puga N, Sánchez González J de J, Ron Parra J, González Eguiarte DR,

761 Holland JB, Medina García G (2008) Climatic adaptation and ecological descriptors of 42

762 Mexican maize races. Crop Sci 48: 1502

763 Salazar-Vidal MN, Acosta-Segovia E, Sánchez-León N, Ahern KR, Brutnell TP, Sawers RJH 764 (2016) Characterization and Transposon Mutagenesis of the Maize (Zea mays) Phol Gene

765 Family. PLoS One 11: e0161882

766 Sanchez G. JJ, Goodman MM (1992) Relationships among the Mexican races of maize. Econ

767 Bot 46: 72-85

768 Sankararaman S, Mallick S, Dannemann M, Prüfer K, Kelso J, Pääbo S, Patterson N, Reich D

769 (2014) The genomic landscape of Neanderthal ancestry in present-day humans. Nature 507:

$770 \quad 354-357$

771 Sankararaman S, Mallick S, Patterson N, Reich D (2016) The combined landscape of Denisovan

772 and Neanderthal ancestry in present-day humans. Curr Biol 26: 1241-1247

773 Sansaloni C, Petroli C, Jaccoud D, Carling J, Detering F, Grattapaglia D, Kilian A (2011)

774 Diversity Arrays Technology (DArT) and next-generation sequencing combined: genome-wide,

775 high throughput, highly informative genotyping for molecular breeding of Eucalyptus. BMC

776 Proc 5: P54

777 Selinger DA, Chandler VL (1999) Major recent and independent changes in levels and patterns

778 of expression have occurred at the $b$ gene, a regulatory locus in maize. Proc Natl Acad Sci U S

779 A 96: 15007-15012

780 Selinger DA, Chandler VL (2001) B-Bolivia, an allele of the maize $b 1$ gene with variable

781 expression, contains a high copy retrotransposon - related sequence immediately upstream. Plant

782 Physiology 1363-1379

783 Sharma M, Cortes-Cruz M, Ahern KR, McMullen M, Brutnell TP, Chopra S (2011)

784 Identification of the $p r l$ gene product completes the anthocyanin biosynthesis pathway of maize.

785 Genetics 188: 69-79

786 Takuno S, Ralph P, Swarts K, Elshire RJ, Glaubitz JC, Buckler ES, Hufford MB, Ross-Ibarra J

787 (2015) Independent molecular basis of convergent highland adaptation in maize. Genetics 200:

Peer) reviewing PDF | (2019:01:34192:1:2:NEW 11 Mar 2019) 
788

789

790

791

792

793

794 795

796

797

798

799

800

801

802

803

804

805

806

807

808

809

810

811

812

813

814

815 Xu G, Wang X, Huang C, Xu D, Li D, Tian J, Chen Q, Wang C, Liang Y, Wu Y, Yang X, Tian 816 F (2017) Complex genetic architecture underlies maize tassel domestication. New Phytol 214: $817 \quad 852-864$

$1297-1312$

Twyford AD, Friedman J (2015) Adaptive divergence in the monkey flower Mimulus guttatus is maintained by a chromosomal inversion. Evolution 69: 1476-1486

Vieira FG, Fumagalli M, Albrechtsen A, Nielsen R (2013) Estimating inbreeding coefficients from NGS data: impact on genotype calling and allele frequency estimation. Genome Res 23: $1852-1861$

Vollbrecht E, Springer PS, Goh L, Buckler ES 4th, Martienssen R (2005) Architecture of floral branch systems in maize and related grasses. Nature 436: 1119-1126

Walsh J, Freeling M (1999) The liguleless2 gene of maize functions during the transition from the vegetative to the reproductive shoot apex. Plant J 19: 489-495

Wang L, Beissinger TM, Lorant A, Ross-Ibarra C, Ross-Ibarra J, Hufford M (2017) The interplay of demography and selection during maize domestication and expansion. Genome Biol.18, 215

Wellhausen EJ (1957) Races of Maize in Central America. National Academies

Wellhausen EJ, Roberts LM, Hernandez E, Mangelsdorf PC (1952) Races of maize in Mexico: their origin, characteristics and distribution. Bussey Institution of Harvard Univ

Whitney KD, Randell RA, Rieseberg LH (2006) Adaptive introgression of herbivore resistance traits in the weedy sunflower Helianthus annuus. Am Nat 167: 794-807

Whitney, KD, Broman KW, Kane NC, Hovick SM, Randell RA, Rieseberg LH (2015) Quantitative trait locus mapping identifies candidate alleles involved in adaptive introgression and range expansion in a wild sunflower. Mol Ecol 24: 2194-2211

Wilkes HG (1972) Maize and its wild relatives. Science 177: 1071-1077

Wu Q, Regan M, Furukawa H, Jackson D (2018) Role of heterotrimeric Ga proteins in maize development and enhancement of agronomic traits. PLoS Genet 14: e1007374

Xia H-B, Wang W, Xia H, Zhao W, Lu B-R (2011) Conspecific crop-weed introgression influences evolution of weedy rice (Oryza sativa f. spontanea) across a geographical range. doi: 10.1371/journal.pone.0016189 


\section{Figure 1}

Gene flow from teosinte mexicana to Mexican highland maize.

(A) Mapping of the regions of introgression $>250 \mathrm{~kb}$ in size to the ten chromosomes of maize (1-10). Colored points indicate the midpoint of regions identified using a $10 \%$ (blue) or $1 \%$ (red) outlier cut-off. Magenta bars show nine regions previously identified by Hufford et al., 2013. The cyan bar shows a Mb-scale region on chromosome 3 identified by Wang et al., 2017. The gray trace on the outermost track indicates local recombination frequency $\left(\log _{2}\right.$ transformed) estimated from the PT $\times$ REV $F_{2}$ population . (B) Size distribution (frequency density) of introgression events using a 10\% (blue) or 1\% (red) outlier cut-off. Events binned by size $<0.5 \mathrm{Mb}, 0.5 \mathrm{Mb}$ to $<1 \mathrm{Mb}(1.0), 1 \mathrm{Mb}$ or greater. Numbers above bars give the number of events in that class. (C) Cumulative gene count as a function of cumulative physical size of $10 \%$ outlier introgression regions, ordered by size. Blue points indicate the cumulative count. The black line shows the expected trend based on total genome size and gene number, under the assumption of a uniform spatial distribution. Alternating gray and white bars indicate size thresholds of the individual events of $0.5 \mathrm{Mb}, 1 \mathrm{Mb}, 1.5 \mathrm{Mb}$ and > $1.5 \mathrm{Mb}$. 
A

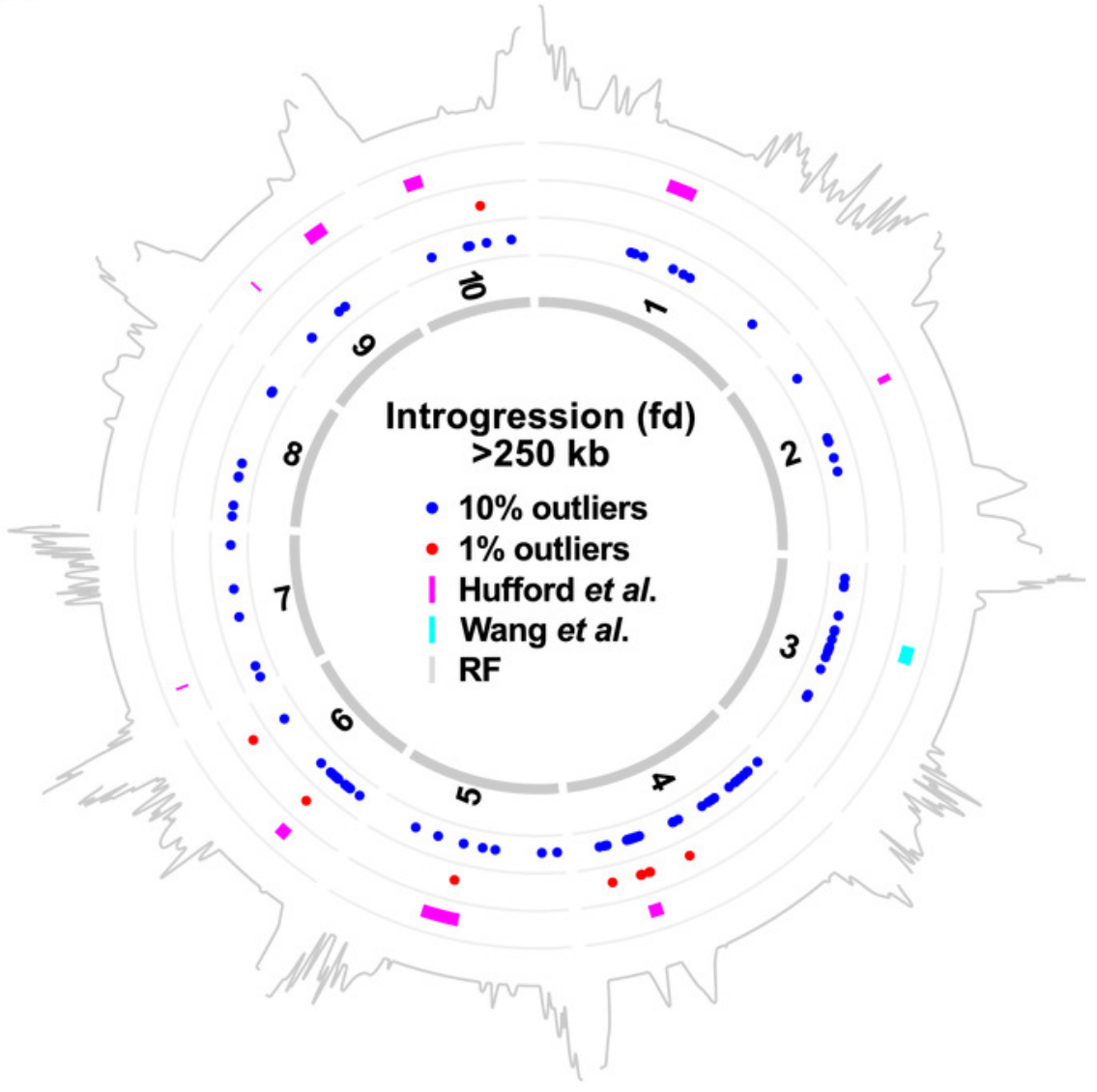

B
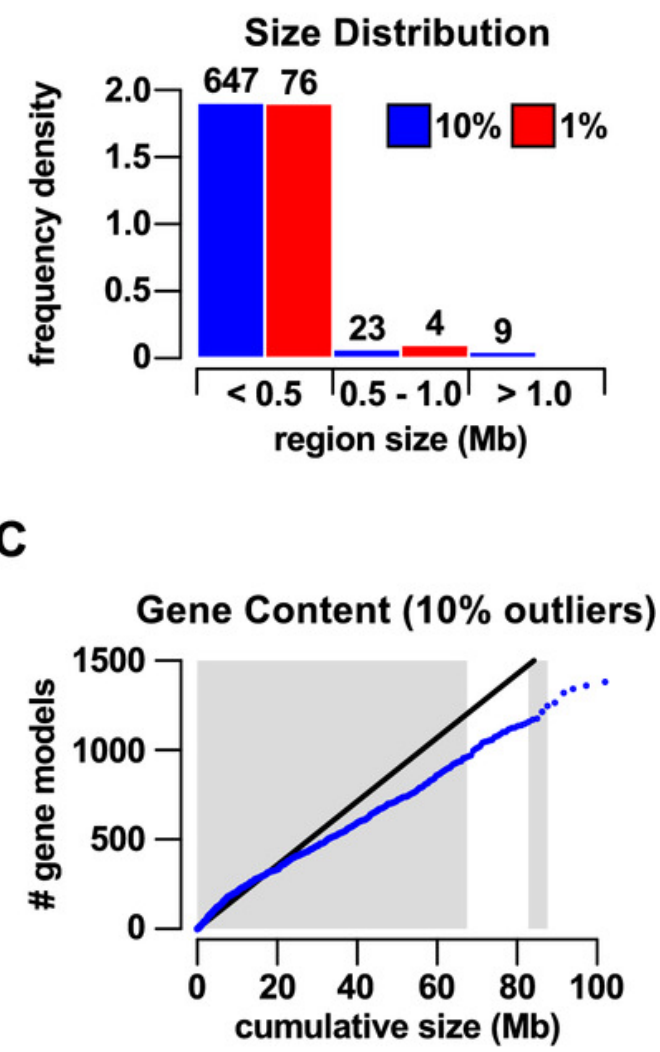


\section{Figure 2}

Large regions of introgression are associated with low genetic recombination.

(A) Local recombination rate (RR) across the physical space of the ten maize chromosomes ( 1 - 10), estimated from the PT $\times$ REV $F_{2}$ population. RR shown from 0 to 2 on a linear blackred-yellow scale. The RR distribution was truncated, with values $>2$ set to 2 (predominantly high values in the telomeric regions). Thirty two introgression events $>500 \mathrm{~kb}$ in size that were identified by concatenation of the top $10 \%$ outlying fd windows are shown as blue line segments to the right of the individual chromosomes. Magenta and cyan line segments show regions previously identified by Hufford et al., 2013 and Wang et al., 2017, respectively. Centromeres shown as open circles. (B) RR as a function of the physical size of introgression events. Events were grouped into size classes, given as the upper threshold on the plot. Boxes show 1st quartile, median and 3rd quartile. Whiskers extend to the most extreme points within $1.5 x$ box length; outlying values beyond this range are not shown. Numbers above the boxes show the number of events in each size class. 
A

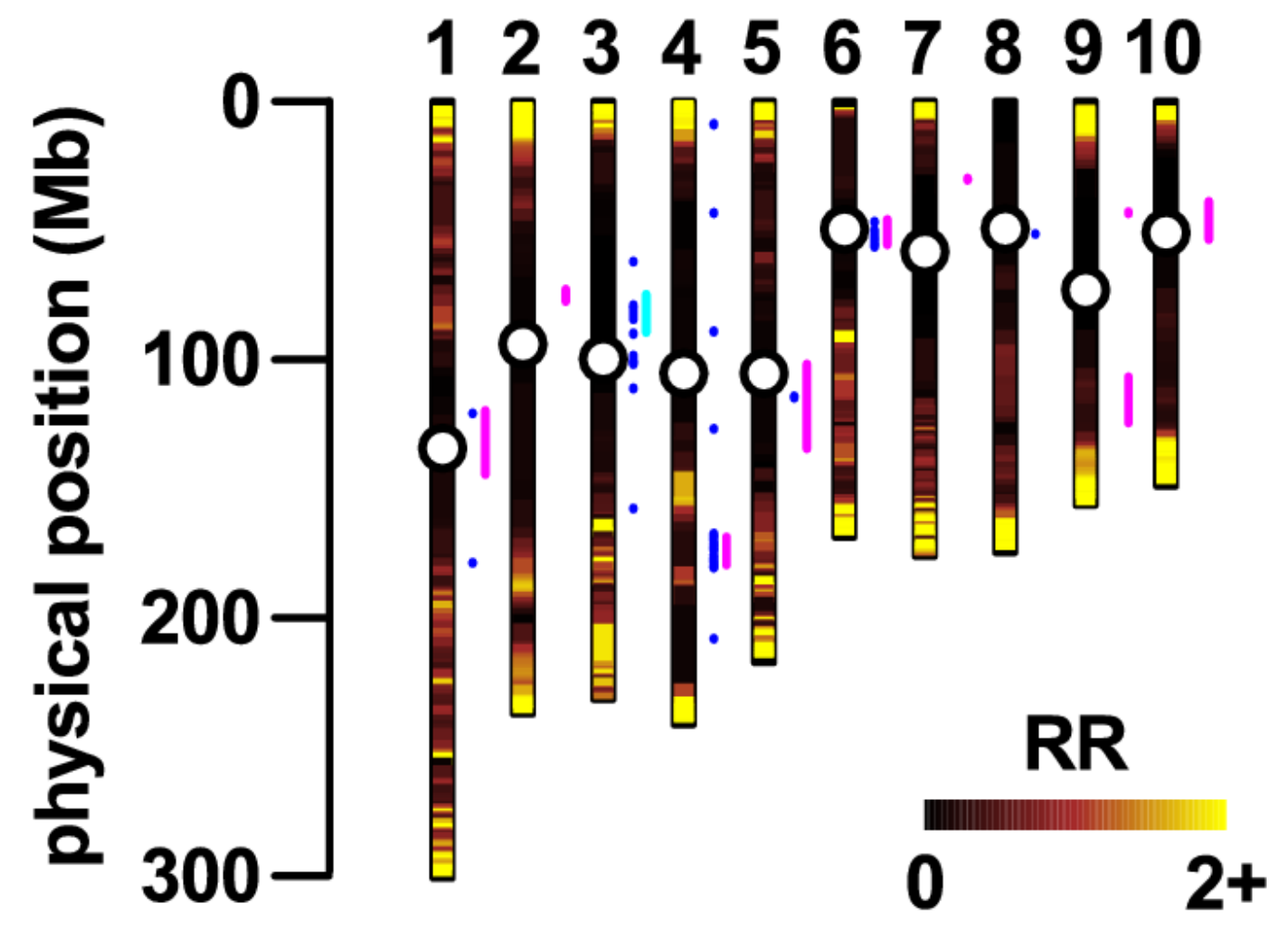

B

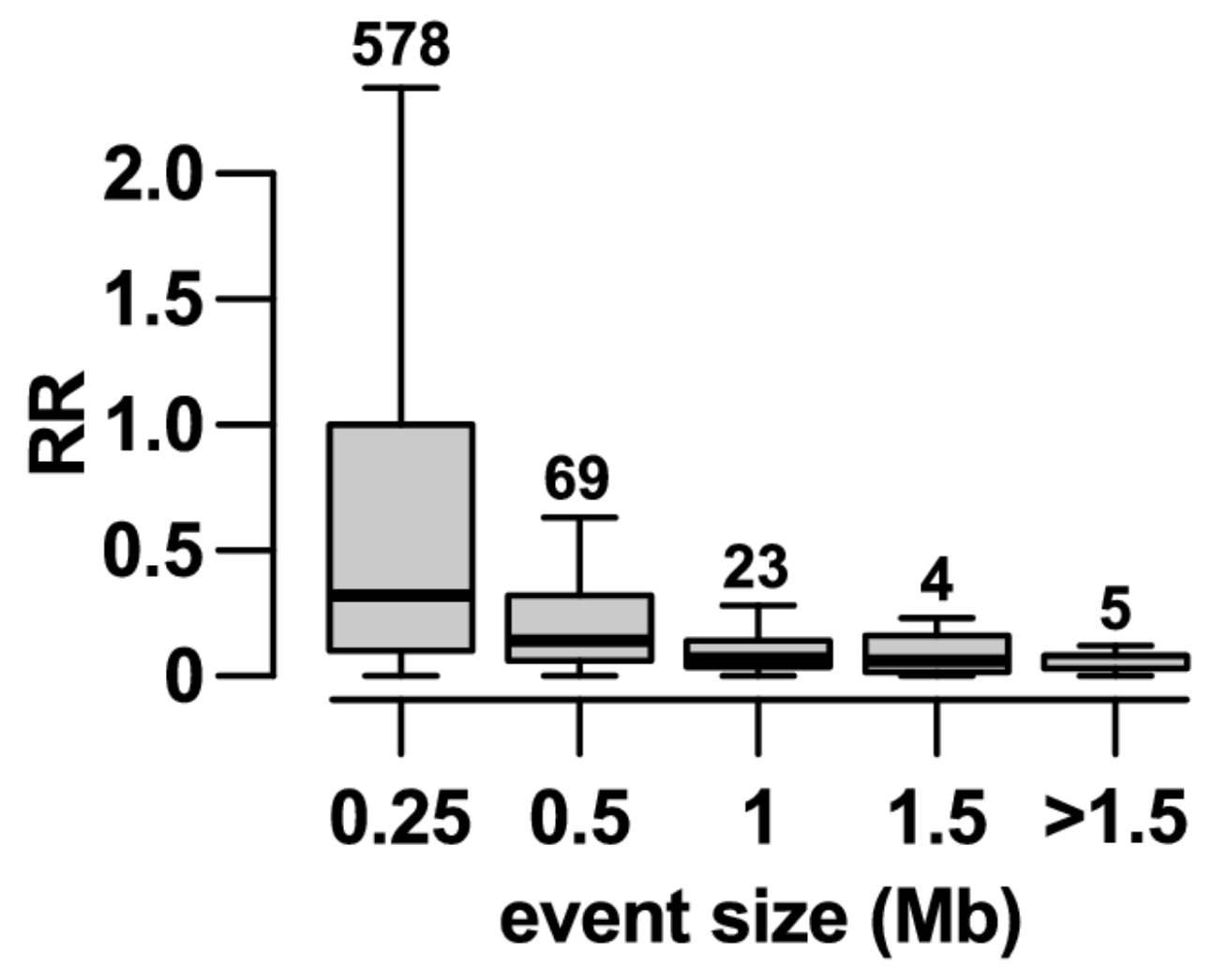




\section{Figure 3}

Introgression events on chromosome 4 co-localize with a previously reported inversion.

Marey plot (black dashed line) of genetic position in map units (mu; left-hand axis, outer) against physical position in $\mathrm{Mb}$ ( $\mathrm{x}$-axis) across chromosome 4. Local recombination rate (RR; solid black line) was calculated as the derivative of the physical-genetic plot (left-hand axis, inner). Introgression from mexicana to Mexican highland maize was estimated as local fd (green line; lowess smoothing of sliding window analysis). The result of a similar analysis substituting South American for Mexican highland maize is also shown (brown line). Introgression events identified by selection and concatenation of the top 1\% or top 10\% outlying windows in the Mexican highland analysis are in red and blue, respectively. The position of the inv4m inversion polymorphism, as previously reported by Hufford et al., 2013, is shown as a gray rectangle. The position of the centromere is indicated as an open circle on the chromosome schematic. 
inv4m

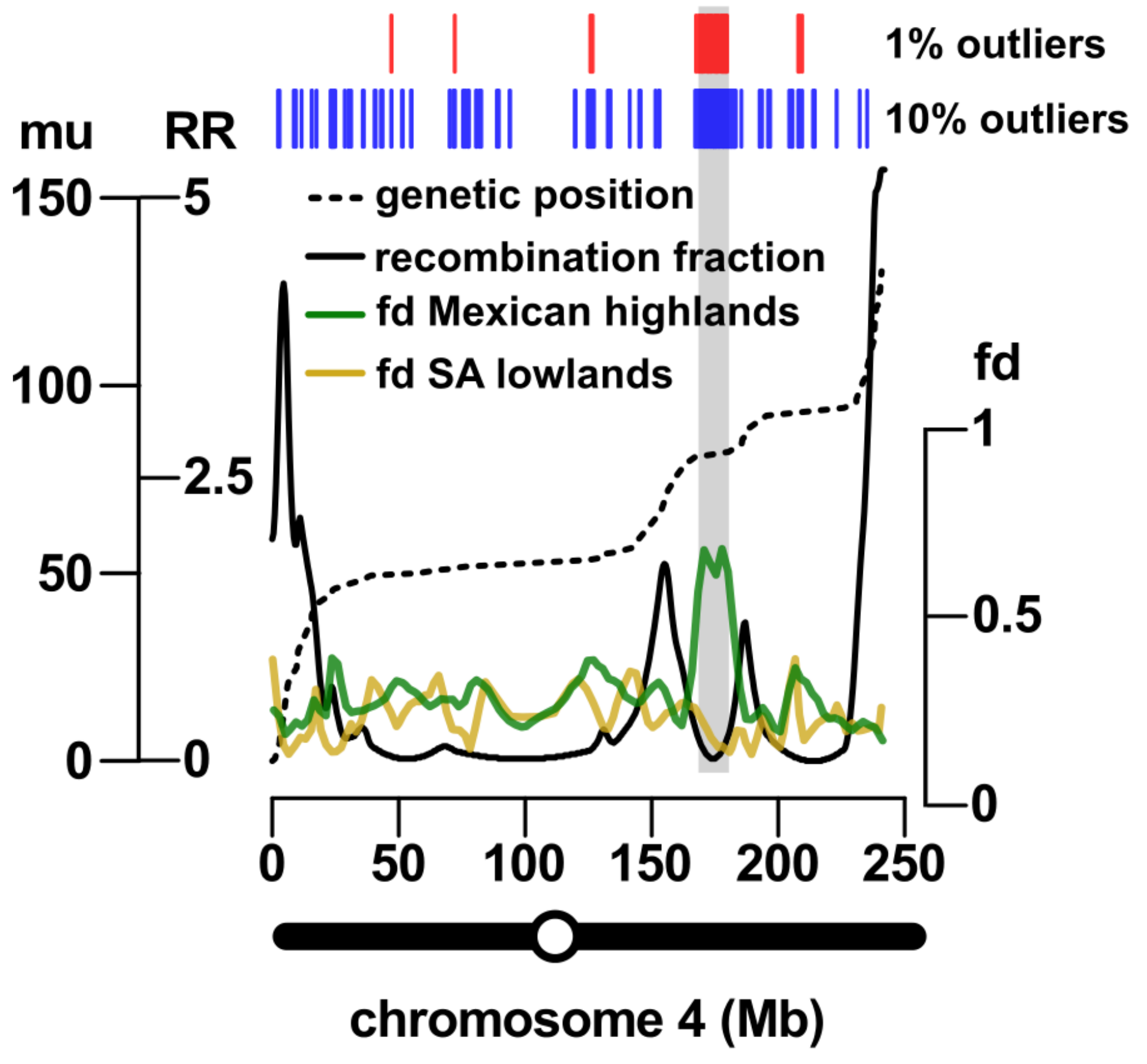




\section{Figure 4}

Genes located in introgression regions differentiate highland and lowland Mexican maize and are enriched for high effect SNPs

(A) $\mathrm{F}_{\mathrm{ST}}$ between Mexican highland and lowland maize populations, as estimated by Takuno et al. (median $\mathrm{F}_{\mathrm{ST}}$ of all SNPs per gene model; 21, 029 gene set), for genes located in regions of direct descent (dir) or introgression (int) events, on the ten chromosomes of maize. Boxes show 1st quartile, median and 3rd quartile. Whiskers extend to the most extreme points within $1.5 x$ box length; outlying values beyond this range are shown as points, including a number of extreme outliers in both direct and introgression regions. (B) The number of high or moderate effect SNPs fixed in the three Mexican highland maize individuals with respect to their distribution in the other samples. Colored boxes indicate SNPs fixed for the alternate allele (blue), the reference allele (red) or segregating (magenta) in a given group. Blanks indicate that SNPs could be not called. Only sets containing greater than 25 SNPs are shown. 
A

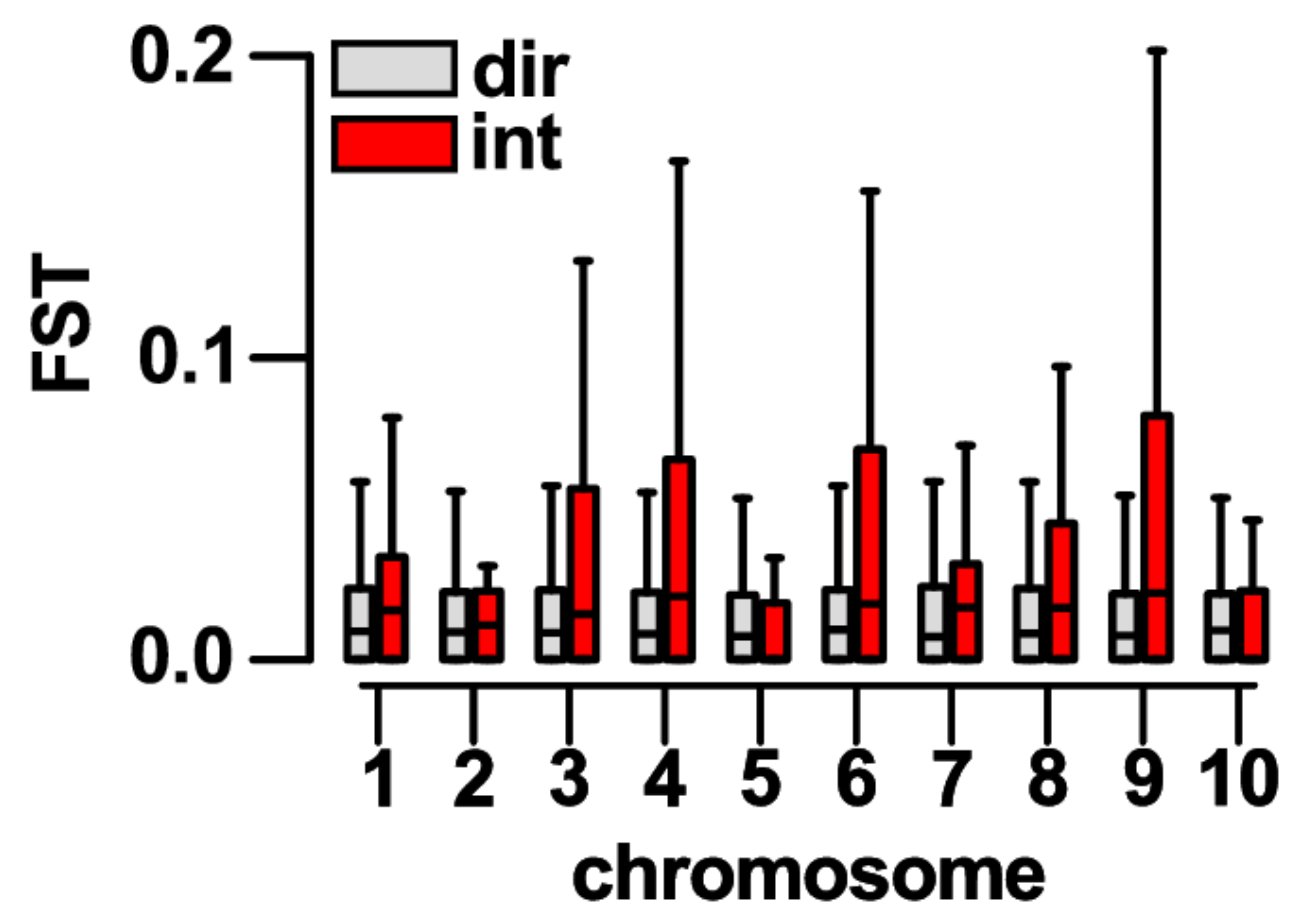

B

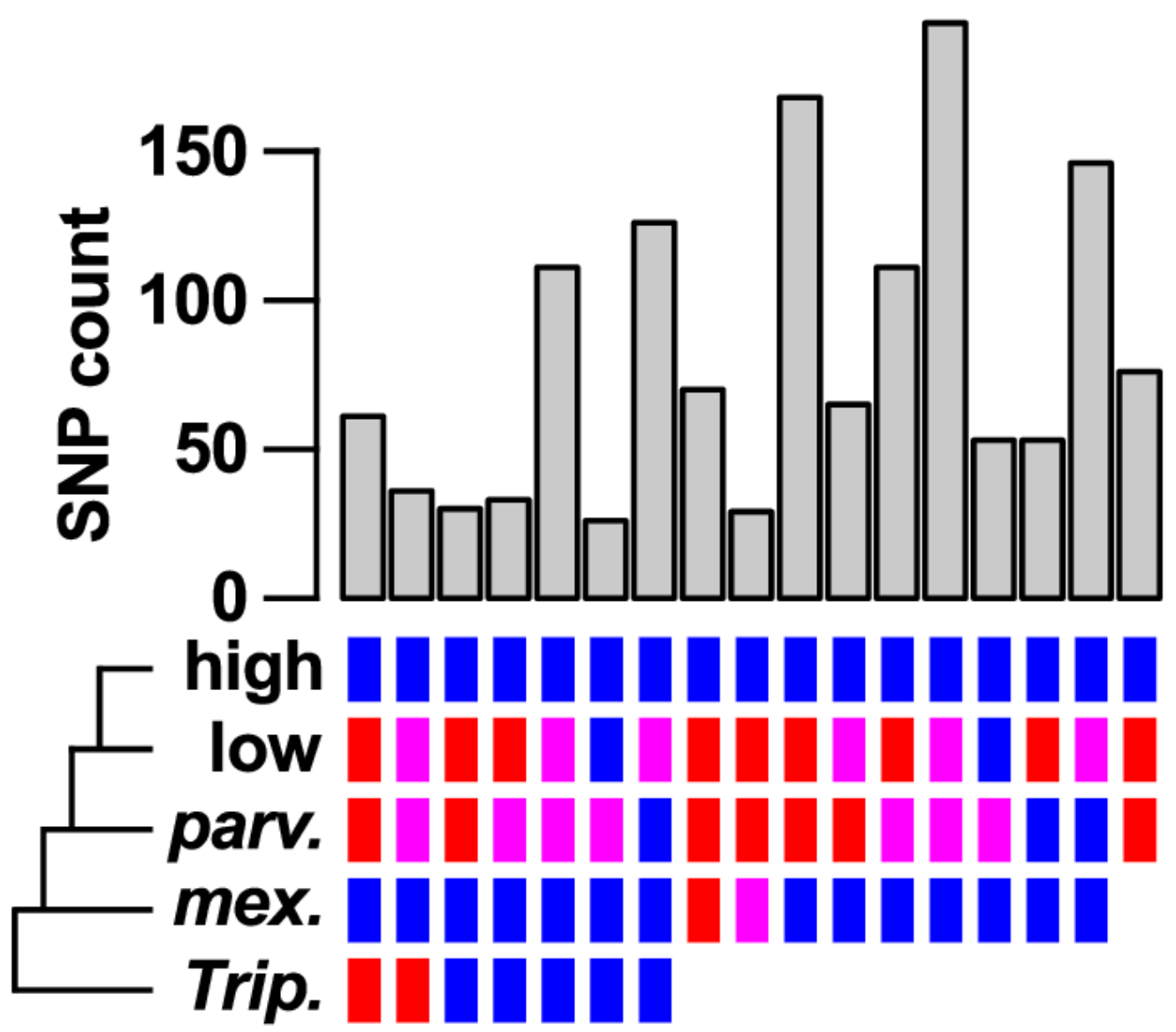




\section{Figure 5}

QTL peaks associated with morphological traits do not co-localize with large-scale introgression events.

(A) Palomero Toluqueño (PT) exhibits the extensive stem pigmentation and pubescence typical of Mexican highland maize, in contrast to (B) the lowland landrace Reventador (RV) which presents a non-pigmented, glabrous stem. Whole-genome QTL scans for the intensity of (C) stem pigmentation (pigment intensity) and (D) the degree of branching of the male inflorescence (tassel branch number). The horizontal axis shows genetic position across the ten maize chromosomes in the PT x RV map, tick-marks indicating marker position, alternating white/gray banding in the plot area indicating chromosomes. Vertical blue lines across the plot area indicate the estimated position of introgression events on the genetic map, line width proportional to event size. The vertical axis shows LOD support for the presence of a QTL. The red trace shows the output from a single-QTL interval scan. The horizontal broken black-lines indicate the 5\% LOD threshold for each trait, as determined by permutation. Major peaks for pigment intensity and tassel branch number are located on chromosomes 2 and 7, respectively. 
A

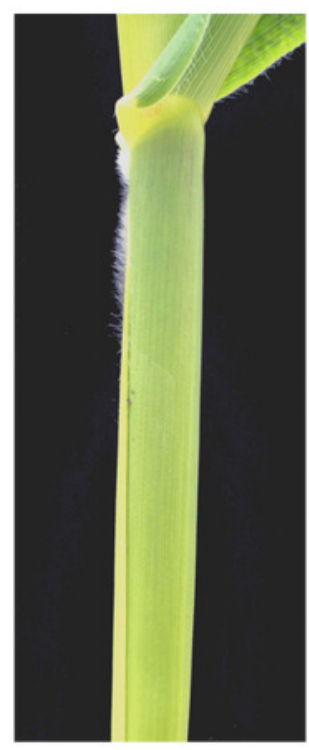

B

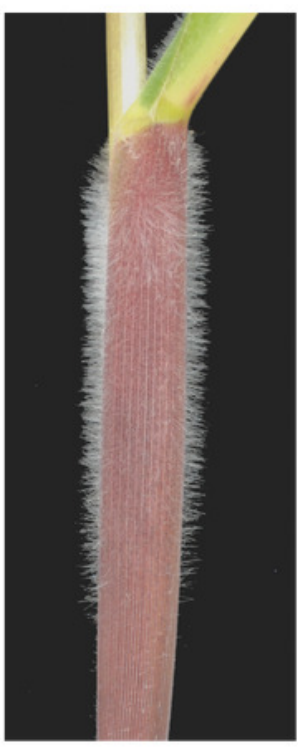

C

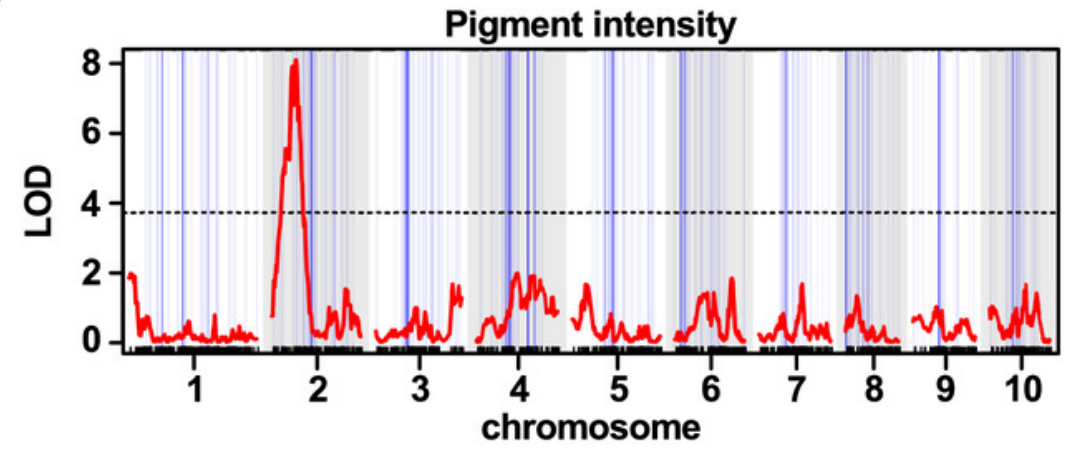

D

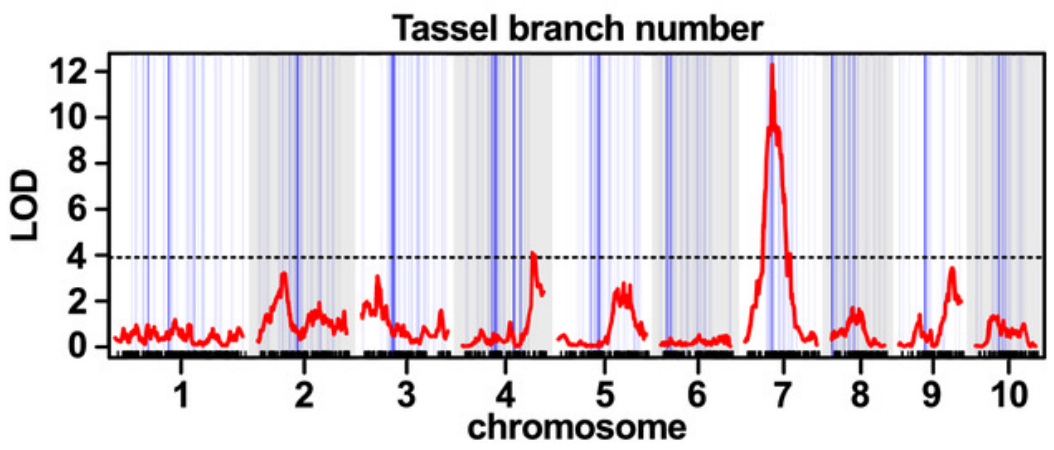




\section{Table 1 (on next page)}

Introgression from mexicana to Mexican highland maize and recombination rate by chromosome 
1 Table 1. Introgression from mexicana to Mexican highland maize and recombination rate

2 (RR) by chromosome

\begin{tabular}{lccccccccc} 
Target & $\begin{array}{c}\text { Size } \\
(\mathrm{Mb})\end{array}$ & $\mathrm{D}$ & $\mathrm{Z}$ & $p$-value & $\begin{array}{c}\text { Number } \\
\text { of } \\
\text { events }^{1}\end{array}$ & $\begin{array}{c}\text { Total } \\
\text { event } \\
\text { size } \\
(\mathrm{Mb})\end{array}$ & $\begin{array}{c}\text { Introgression } \\
(\%)\end{array}$ & $\begin{array}{c}\text { Map } \\
\text { length } \\
(\mathrm{cM})\end{array}$ & $\begin{array}{c}\mathrm{RR} \\
(\mathrm{cM} / \mathrm{Mb})\end{array}$ \\
\hline Chr1 & 301 & 0.066 & 6.0 & $<0.001$ & 84 & 9.3 & 3.1 & 208 & 0.69 \\
Chr2 & 238 & 0.063 & 5.7 & $<0.001$ & 67 & 5.7 & 2.4 & 144 & 0.61 \\
Chr3 & 232 & 0.075 & 5.0 & $<0.001$ & 85 & 2 & 8.8 & 138 & 0.60 \\
Chr4 & 242 & 0.133 & 5.4 & $<0.001$ & 90 & 24.8 & 10.2 & 130 & 0.54 \\
Chr5 & 218 & 0.072 & 5.5 & $<0.001$ & 72 & 8.9 & 4.1 & 142 & 0.65 \\
Chr6 & 169 & 0.104 & 5.2 & $<0.001$ & 74 & 11.5 & 6.8 & 113 & 0.67 \\
Chr7 & 177 & 0.055 & 4.5 & $<0.001$ & 51 & 5.1 & 2.9 & 116 & 0.66 \\
Chr8 & 175 & 0.041 & 2.6 & 0.009 & 61 & 6.9 & 4.0 & 86 & 0.49 \\
Chr9 & 157 & 0.028 & 1.7 & 0.09 & 52 & 4.7 & 3.0 & 100 & 0.64 \\
Chr10 & 150 & 0.051 & 3.1 & 0.002 & 43 & 4.6 & 3.0 & 97 & 0.65 \\
Total & 2060 & & & & 679 & 102 & 5.0 & 1275 & 0.62 \\
\hline 1
\end{tabular}

3

1. Concatenated $10 \%$ outliers. 2 . Based on physical size. 
Table 2 (on next page)

Selected classic genes located in introgression events 
1 Table 2. Selected classic genes located in introgression events

\begin{tabular}{|c|c|c|c|c|c|c|}
\hline Gene & ID & Function & $\mathrm{Chr}$ & Pos $(\mathrm{Mb})$ & Top $10 \%$ & Top $1 \%$ \\
\hline$A 1$ & GRMZM2G026930 & Pigments & 3 & 216 & $\mathrm{X}$ & \\
\hline Acco20 & GRMZM2G126732 & Hormones (Et) & 4 & 178 & $\mathrm{X}$ & $\mathrm{X}$ \\
\hline$B x 8$ & GRMZM2G085054 & Defense & 4 & 3 & $\mathrm{X}$ & \\
\hline Cle24 & GRMZM2G123818 & Morphology & 4 & 170 & $\mathrm{X}$ & \\
\hline$C t 2$ & GRMZM2G064732 & Morphology & 1 & 16 & $\mathrm{X}$ & \\
\hline$D 8$ & GRMZM2G144744 & Hormones (GA) & 1 & 266 & $\mathrm{X}$ & \\
\hline Fea3 & GRMZM2G166524 & Morphology & 3 & 291 & $\mathrm{X}$ & \\
\hline$F l 3$ & GRMZM2G006585 & Grain development & 8 & 52 & $\mathrm{X}$ & \\
\hline$G i 2$ & GRMZM5G844173 & Flowering & 3 & 9 & $\mathrm{X}$ & \\
\hline Kol & GRMZM2G059308 & Hormones (GA) & 9 & 80 & $\mathrm{X}$ & \\
\hline $\mathrm{Nal}$ & GRMZM2G449033 & Hormones (Br) & 3 & 179 & $\mathrm{X}$ & \\
\hline Natl1 & GRMZM2G455658 & Hormones (Br) & 4 & 169 & $\mathrm{X}$ & $X$ \\
\hline$O 1$ & GRMZM2G449909 & Grain development & 4 & 177 & $\mathrm{X}$ & \\
\hline Orp2 & GRMZM2G005024 & Grain development & 10 & 84 & $\mathrm{X}$ & \\
\hline Sbel & GRMZM2G088753 & Grain development & 5 & 63 & $\mathrm{X}$ & \\
\hline Ss 5 & GRMZM2G130043 & Grain development & 4 & 173 & $\mathrm{X}$ & \\
\hline Su4 & GRMZM2G090905 & Grain development & 6 & 145 & $\mathrm{X}$ & \\
\hline Phol;2a & GRMZM2G466545 & Nutrition & 4 & 172 & $\mathrm{X}$ & $\mathrm{X}$ \\
\hline Tul & GRMZM2G370777 & Morphology & 4 & 179 & $\mathrm{X}$ & $\mathrm{X}$ \\
\hline
\end{tabular}


Table 3 (on next page)

QTL associated with plant morphology and flowering time 
1 Table 3. QTL associated with plant morphology and flowering time

\begin{tabular}{|c|c|c|c|c|c|c|}
\hline QTL & Chr & $\begin{array}{l}\text { Peak } \\
(\mathrm{Mb})\end{array}$ & $\begin{array}{l}\text { 95\% Interval } \\
(\mathrm{Mb})\end{array}$ & $\begin{array}{l}\text { Var } \\
(\%)\end{array}$ & LOD & $\begin{array}{l}\text { Candidate } \\
\text { gene }\end{array}$ \\
\hline qINT-2 & 2 & 19 & $12-21$ & 23 & 9.2 & $B 1$ \\
\hline qPAT-2 & 2 & 13 & $12-20$ & 18 & 6.7 & $B 1$ \\
\hline qTBN-2 & 2 & 18 & $3-196$ & 8 & 4.0 & \\
\hline qTBN-7 & 7 & 98 & $37-118$ & 31 & 13.2 & Ral \\
\hline qTL-4 & 4 & 30 & $10-155$ & 10 & 3.8 & \\
\hline qTL-5 & 5 & 2 & $1-3$ & 12 & 4.5 & \\
\hline qDTA-8 & 8 & 117 & $1-125$ & 14 & 4.5 & $Z c n 8$ \\
\hline
\end{tabular}

2 